\title{
أثر المتغيرات الاقتصادية في مؤشر سوق الأوراق المالية \\ -دراسة تطبيقية-
}

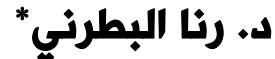

ملخص

هدفت الدر اسة إلى تحديد أثز المتغير ات الاقتصادية الكلية: (معدل الناتج المحلي الإجمالي، ومعدل التضخم، ومعدل الفائدة على الودائع) في أداء مؤشر سوق الأوراق المالية المصرية EGX 30 . اعتمدت الباحثة على المنهج الوصفي التحليلي، وذلك بالنطبيق على البيئة المصرية، خلا الفترة الممتدة ما بين (2010م-2019م).وقد تمَّ الاعتماد على البرنامج الإحصائي SPSS الإصدار 24 واختبار فرضية الدراسة باستخدام اختبار الانحدار الخطي المتعدد. وقد توصلت الدراسة EGX إلى وجود أثر إيجابي ذي دلالة معنوية لمعدل الفائدة على الودائع في أداء مؤشر سوق الأوراق المالية المصرية 30، حيث اتفقت الدراسة الحالية مع معظم الدراسات السابقة في وجود أثز إيجابي لمعدل الفائدة على الودائع في أداء مؤشر سوق الأوراق المالية. عدم وجود أثر ذي دلالة معنوية لكل من معدل الناتج المحلي الإجمالي ومعدل التضخم في أداء مؤشر سوق الأوراق المالية المصرية EGX 30 وقد اختلفت بذلك مع دراسة (Rashed et al, 2012) التي نوصلت إلى وجود أثز سلبي لكل من معدل التضخم ومعدل الفائدة على الودائع في أداء مؤشر سوق الأوراق المالية. وقد أوصت الدراسة بــرورة قيام السلطة النقدية بالأخذ بالحسبان الآثار الناجمة عن التغير في أسعار الفائدة على نشاط سوق الأوراق المالية عند صياغتها لأي قزارات تهدف إلى تحقيق النمو الاقتصادي.

الكلمات المفتاحية: مؤشر سوق الأوراق المالية -الناتج المحلي الإجمالي -معدل التضخم-معدل الفائدة -السياسة النقدية.
\end{abstract}

\section{The Impact of Economic Variables on the Financial Stock Market Index}

\section{Abstract}

The study aimed to determine the impact of macroeconomic variables (GDP rate, inflation rate, interest rate on deposits) on the performance of the Egyptian stock market index EGX 30. The researcher relied on the descriptive and analytical approach, applying it to the Egyptian environment, during the period (2010-2019. The study was relied on SPSS version 24 statistical program and tested the study hypothesis using multiple linear regression test. The study found The presence of a positive and significant effect of the interest rate on deposits on the performance of the Egyptian stock market index EGX 30, as the current study agreed with most of the previous studies in the existence of a positive effect of the interest rate on deposits on the performance of the stock market index. The absence of a significant effect of both the gross domestic product and the inflation rate on the performance of the Egyptian stock market index EGX 30, and this differed with a study (Rashed et al, 2012) that found a negative impact for both the inflation rate and the interest rate On deposits in the stock market index performance. The study recommended that the monetary authority should take into consideration the effects resulting from the change in interest rates on the activity of the stock market when formulating any decisions aimed at achieving economic growth.

Key words: Stock Market Index- Gross Domestic Product- Inflation Rate-Interest RateMonetary Policy. 


\section{مقدمة}

تتعرض البيئة الاقتصادية و المالية إلى تغير ات مستمرة ناتجة عن حدوث تقلبات اقتصادية بصورة دورية، وحدوث ثقلبات في متغير ات الاقتصاد الكلي المتمثلة بـ: (الناتج المحلي، والتضخم، وأسعار الصرف) التي تؤثر بشكل كبير في مستويات النشاط الاقتصادي و المالي، وبالتالي، على حركة واتجاه المؤشرات الاقتصادية و المؤشر ات المالية في الأسواق المالية.

إذ تعد الأسواق المالية إحدى الأدوات المهمة في القطاع المالي الذي يمثل العمود الفقري لعملية التتمية

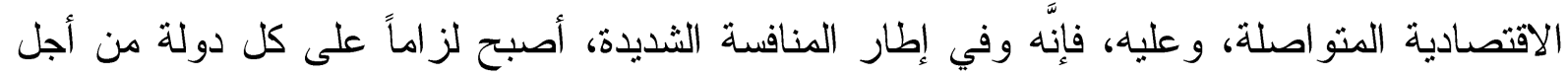
تحقيق التتمية الاقتصادية و المحافظة على مكانتها أن تولي اهتماماً كبيراً لأسواق المال، وتعمل على لهى تطويرها وعصرنتها على جميع المستويات، إلى جانب العمل على زيادة الأدوات المالية المتداولة و تنويعها.

\section{مشكلة الدر اسة}

تؤدي الأسواق المالية دوراً بالغًا الأهمية في اقتصاديات الدول المتقدمة والنامية على حد سواء، وذلك لما تقدمه هذه الأسواق من دور مهم في حشد المدخرات و إعادة توجيهها في قنو ات استثمارية تعمل على دعم الاقتصاد وتحقيق الرفاهية للأفراد، ونظر اً لتعدد العو امل المؤثرة في الأسواق المالية، ولعل أبرزها المتغير ات الاقتصادية الأمر الذي استدعى إجر اء هذه الدر اسة، ومن هنا تكمن مشكلة الدر اسة في الإجابة على التساؤل الآتي:

هل تؤثر المتغيرات الاقتصادية الكلية: (معدل الناتج المحلي الإجمالي، ومعدل التضخم، معدل الفائدة على الودائع) في أداء مؤشر سوق الأوراق المالية المصرية 30 EGX

أهداف الدر اسة

هدفت الدراسة إلى تحديد أثز المتغيرات الاقتصادية الكلية: (معدل الناتج المحلي الإجمالي، ومعدل التضخم، ومعدل الفائدة على الودائع) في أداء مؤشر سوق الأوراق المالية المصرية EGX 30. أهمية الدر اسة تكمن أهمية الدر اسة في جانبين: أهمية علمية: تتمثل بإغناء الرصد الأكاديمي و المكتبة العلمية بمو اضيع لم تحظَ بالاهتمام الكافي في بيئة الأعمال المصرية. 
أهمية عملية: تتمثل فيما سينم التوصل إليه من نتائج، وما ينجم عنها من توصيات تسهم في تحديد

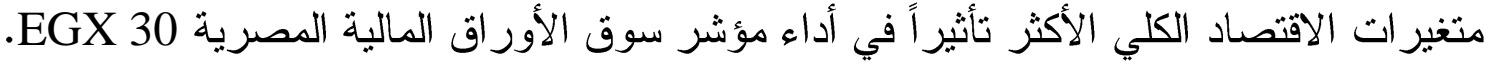

فرضية الدراسة

يوجد أثز ذو دلالة معنوية للمتغير ات الاقتصادية الكلية: (معدل الناتج المحلي الإجمالي، ومعدل التضخم،

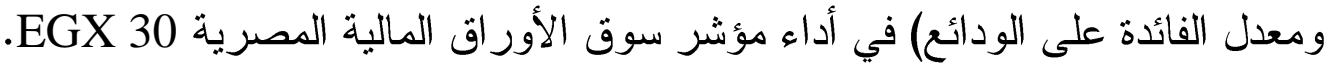

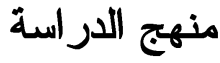

تمّ الاعتماد على المنهج الوصفي التحليلي لنحقيق أهداف الدراسة والإجابة عن فرضياتها، حيث يعبر المنهج الوصفي التحليلي عن الظاهرة المراد دراستها، كما توجد في الواقع، ويهنم بوصفها وصفاً دقيقاً،

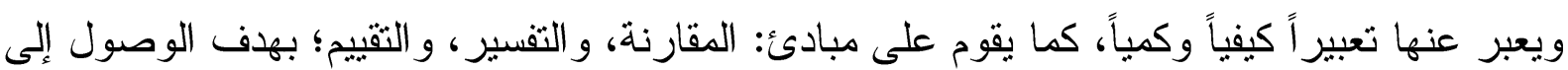

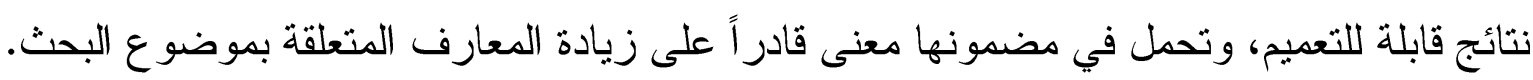
محددات الدراسة تعذر على الباحثة تتاول متغيرات أخرى للاقتصاد الكلي كسعر الصرف، ومعدل النمو الاقتصادي، ومعدل البطالة، لتعذر الحصول على بعض بيانات السلسلة الزمنية (2010م-2019م)، وعدم اكتمالها

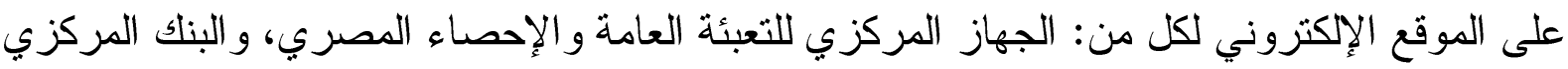
المصري، و البنك الدولي. أسلوب جمع البيانات

تم الحصول على قيم كل من: معدل الناتج المحلي الإجمالي، ومعدل التضخم، ومعدل الفائدة على الودائع بالاعتماد على البيانات الإحصائية المنشورة على الموقع الإلكتروني لكل من: الجهاز المركزي للتعبئة

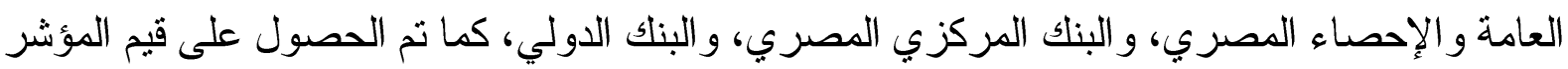
EGX 30 وقد تمَّ الاعتماد على البرنامج الإحصائي SPSS الإصدار 24 واختبار فرضية الدر اسة باستخدام اختبار الانحدار الخطي المتعدد.

الدراسات السابقة 1- دراسة (Barakat \& et.al, 2016) هدفت الدراسة إلى تسليط الضوء على العلاقة بين أسواق

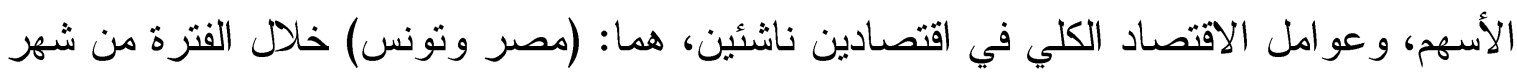

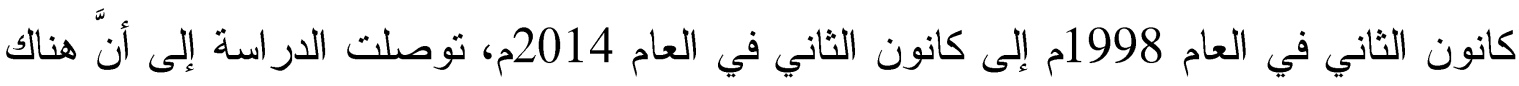


علاقة سببية بين مؤشر سوق الأوراق المالية وكل من: مؤشر أسعار المستهلك (CPI)، وسعر

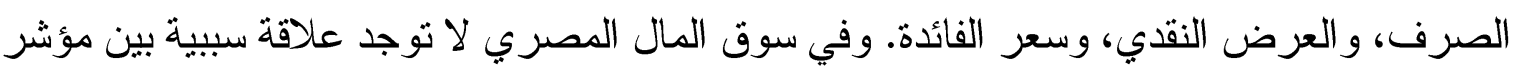
أسعار المستهلك ومؤشر سوق الأسهم في سوق المال التونسي. 2- دراسة (Tiryaki \& et.al, 2017) في تركيا، هدفت الدراسة إلى تحديد العلاقة السببية بين

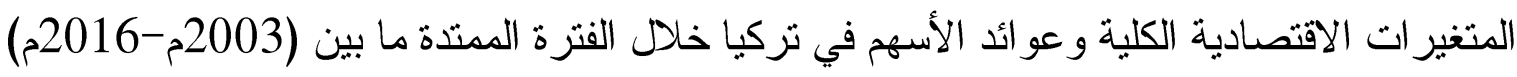

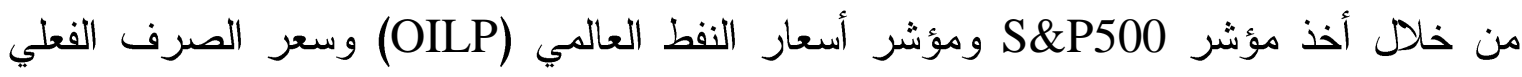

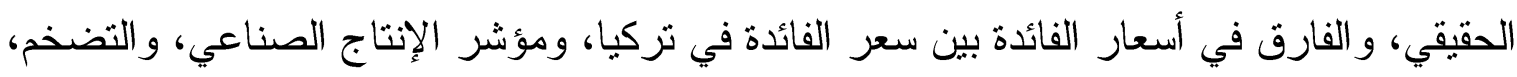

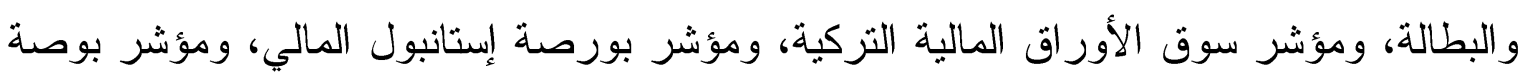

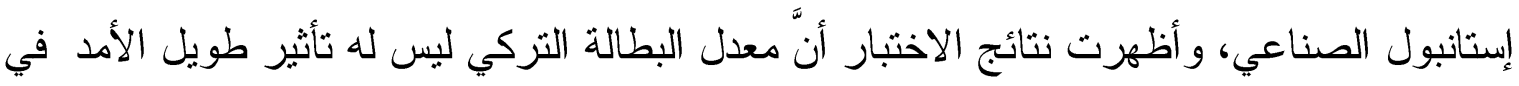
عو ائد الأسهم التركية. 3- دراسة (Rashed et al., 2012) في الباكستان التي هدفت إلى بحث العلاقة بين معدل التضخم

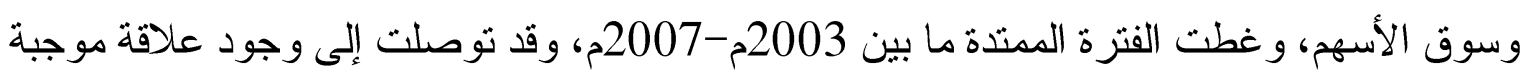
بين معدل التضخم وأسعار الأسهم. 4- در اسة (Muthike and Sakwa, 2011) في سوق الأسهم الكيني التي توصلت إلى وجود علاقة سلبية بين مؤشر السوق وكل من: النضخم، والناتج المحلي الإجمالي، ووجود علاقة إيجابية بين:

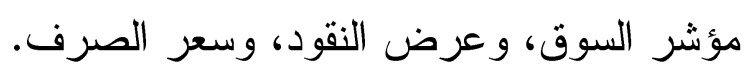
5- در اسة (El-Nader and Alraimony, 2012) في الأردن، التي هدفت إلى تحديد أثر متغير ات

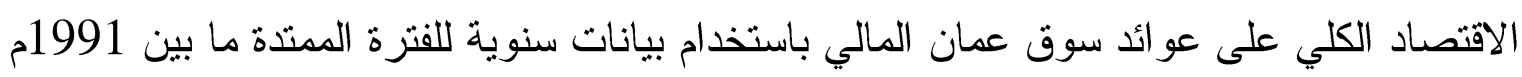
إلى 2010م، وقد توصلت الدراسة إلى وجود أثر سلبي لكل من: عرض النقان النقود، ومؤشر أسعار المستهلك، وسعر الصرف، وسعر الفائدة على عوائد سوق عمان المالي. 6- دراسة (صالح \& نايف، 2020م) في العراق، التي هدفت إلى قياس أثر التغير في: الناتج المحلي

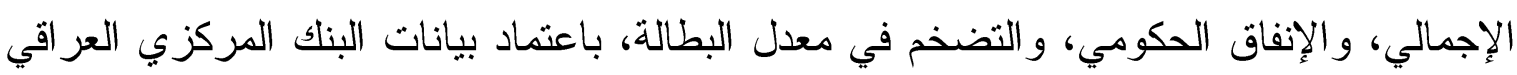

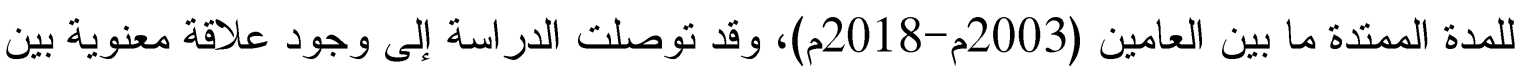
المتغيرات المستقلة ومعدل البطالة، وإن المتغيرات المستقلة كان نأثير ها محدوداً في معدل البطالة.

إن ما يميز الدراسة الحالية شمولية المتغيرات التي درستها، حيث تتاولت متغيرات اقتصادية عدة

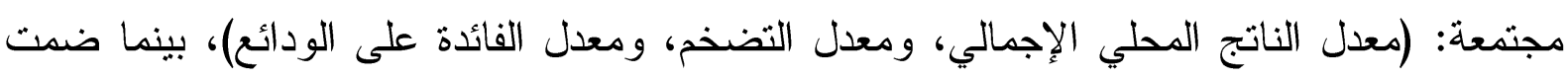

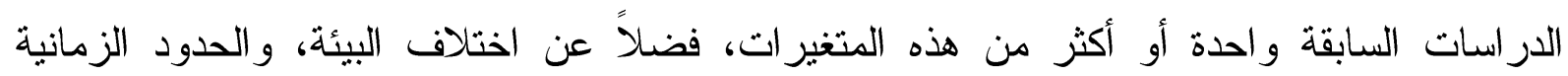
و المكانية، وعلى حسب علم الباحثة، فإنها من أو ائل الدراسات التي تمَّت في بيئة الأعمال المصرية. 
الإطار النظري

\section{أولاً: مفهوم مؤشر سوق الأوراق المالية}

يمثل مؤشر السوق مرجعاً للمستثر عن سوق المال، أو لمجموعة محددة من الأسهم، وذلك إزاء الأداء

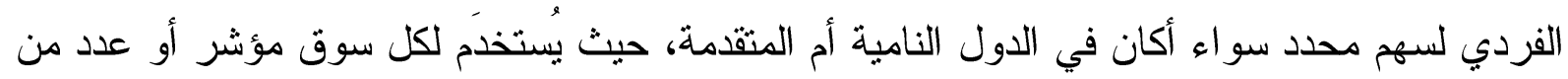

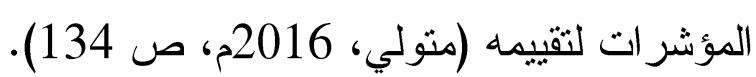
يعرف مؤشر السوق بأنه عبارة عن أداة تستعمل للتعرف على اتجاهات وسلوك السوق المالية بصدق،

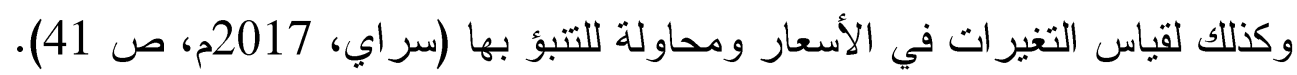
كما عُرِّف بأنه قيمة رقمية تقيس التَّير ات الحادثة في سوق المال، ويتم تكوينه وتحديد قيمته في مرحلة

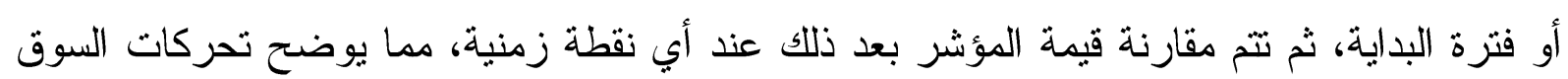

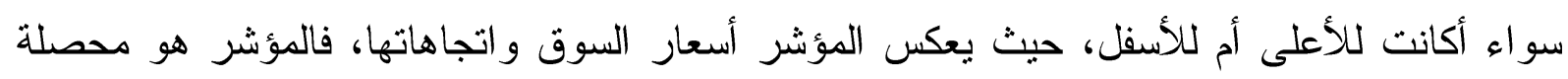
للتغير ات التي تحدث في أسعار الأسهم خلال فترة زمنية محددة بما يساعد في كثف الاتجاه العام للسوق (بن عمر، 2013م، ص 63).

ثانياً: مزايا مؤشر سوق الأوراق المالية

تعبر مؤشرات الأسواق المالية عن الحالة الاقتصادية العامة للاولة ومن المقاييس المهمة التي تعكس حجم الاقتصاد ومستويات الثفافية و الكفاءة في التشغيل والإدارة، كما أنها توفر منظور اً تاريخياً عن أداء السوق، حيث يمد المستثرين بنظرة أكثر شمولية ودقة عن قرار اتهم الاستثارية، حيث تساعد المؤشرات المستثرين الذين لا يستطيعون تحديد أي الأسهر التي سوف يشترونها في عملية اتخاذ قراراتهم

$$
\text { الاستثمارية (متولي، 2016م، ص 135). }
$$

كما يكتسب المؤشر العام للسوق المالي أهية كبيرة لمختلف المتعاملين في السوق المالية، إذ ينم تقييم نشاط السوق من خلال متابعة مؤشرات الأسواق، بما بساعد في تحديد القرارات الاستثمارية بالنسبة

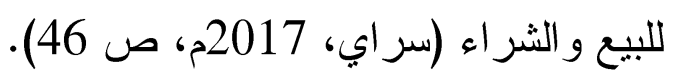
كما تؤدي مؤشرات الأسواق المالية دوراً فاعلاً في عمليات تداول الأوراق المالية في الأسواق المالية انطلاقاً من كونها تعكس الأسعار وحركتها، كما تعد تلخيصاً لأداء الأسواق المالية كونه يعكس أسعار أسهم الشركات في جميع القطاعات الاقتصادية، ويلخص أداءها بمعايير ومؤشرات رقمية قابلة للمقارنة، 
كما بساعد المؤشر القائمين على الأسواق المالية و المشاركين فيها بإعادة تتظيم السوق، من خلال عمليات المضاربة التي تحدد العناصر التي أدَّت إلى انحراف الأسعار وتصويبها باتجاه يعكس الأسعار بدقة فئة (كهينة، 2016م، ص 65).

ثالثاً: استخدامات مؤشرات سوق الأوراق المالية

تستخدم مؤشرات سوق الأوراق المالية لمتابعة أداء السوق أو القطاعات التي يتكون منها السوق، كما يمكن استخدامه كدليل للحكم على أداء مديري الاستثمار، فضلاً عن استخدام هذا المؤشر لقياس العلاقة بين مؤشرات الأدوات المالية المختلفة ولدول مختلفة، وتبرز أهية هذا الأمر عند إنشاء المحافظ المالية التي تركز سياستها الاستثمارية على توزيع الاستثمار بين مختلف الأدوات وبين العديد من الدول (الزبيدي، و المعموري، 2011م، ص سن 139). وبالتالي، تتعدد استخدامات مؤشرات سوف الأوراق المالية التي تهم المستثمرين الأفراد وغيرهم من الأطر اف التي تتعامل في أسواق رأس المال، ومن أهم تلك الاستخدامات الآتي: أ- الحكم على أداء المديرين المحترفين: إنه وفق فكرة التتوع الساذج يمكن للمستثر الذي يمنالك محفظة

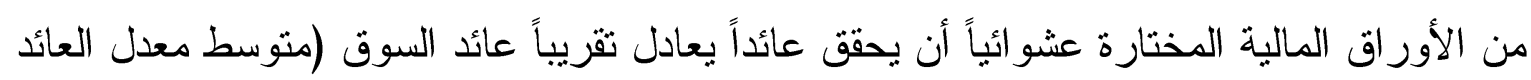

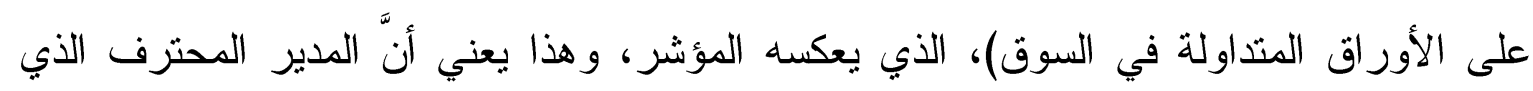
يستخدم أساليب منقدمة في التتويع يتوقع منه أن يحقق عائداً أعلى من منوسط عائد السوق (كهينة،

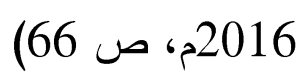
ب-التتبؤ بالحالة التي ستكون عليها السوق: إذا أمكن للمحلل معرفة طبيعة العلاقة بين بعض المتغيرات

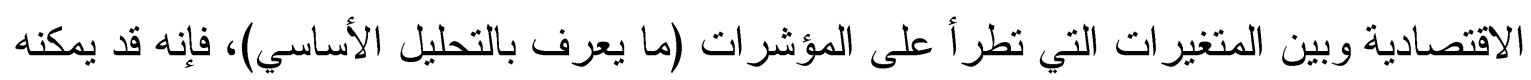

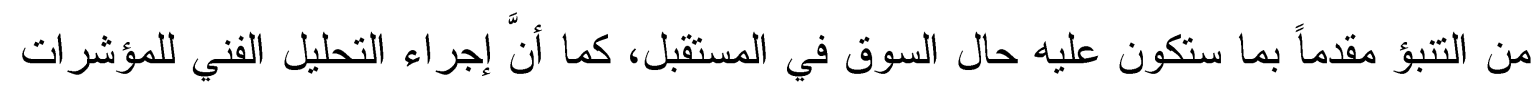
التي تقيس حالة السوق قد تكثف عن وجود نمط للتغيرات التي تطر أ عليه، حيث يقوم هذا التحليل على تتبع حركة الأسعار في الماضي؛ بهدف اكتثاف نمط لتلك الحركة يمكن منه تحديد النوقيت السليم للقرار الاستثماري في المستقبل، إذا ما توصل المحلل لمعرفة هذا النمط، يمكنه عندئذ التتبؤ

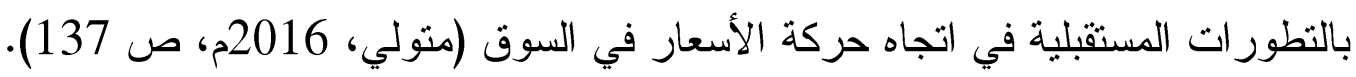
ت-علاقات المتغيرات الاقتصادية بالمؤشر السوقي: حيث يسهم المؤشر السوقي في النعرف على نلك الك

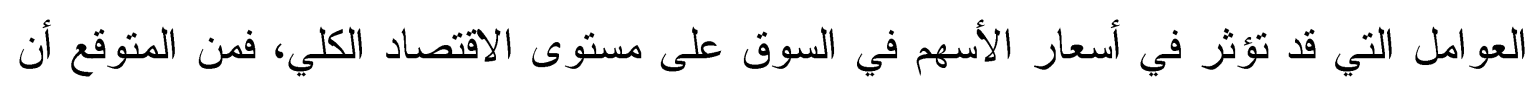


يكون لعرض النقود في المجتمع نأثثره في أسعار الأسهم وتحركاتها، وكذلك معدلات التضخم وأسعار

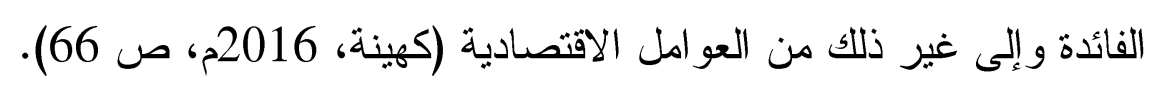
ث-تقدير مخاطر المحفظة: يمكن استخدام المؤشرات لقياس المخاطر المنتظمة لمحفظة الأوراق المالية، وهي: العلاقة بين معدل العائد لأصول خطرة، ومعدل العائد لمحفظة السوق المكونة من أصول

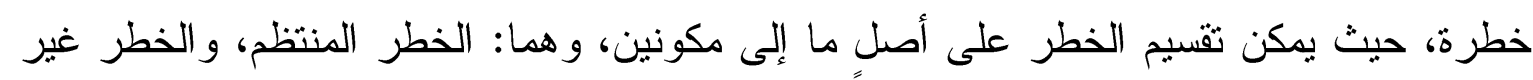

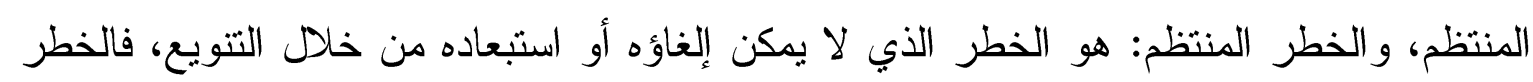

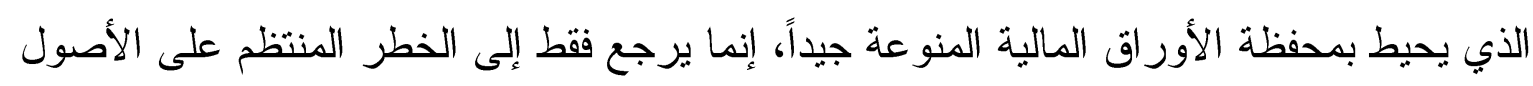
الموجودة بالمحفظة (متولي، 2016م، ص 137).

رابعاً: مؤشر EGX 30 في البورصة المصرية

مؤشر EGX 30 (المعروف بمؤشر CASE 30 سابقاً) هو مؤشر تمّ تصميمه وحسابه بمعرفة البورصة

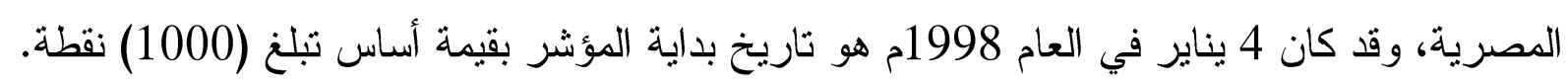
بدأت البورصة المصرية في نشر بياناته اعتبار اً من 2 فبراير في العام 2003م عن طريق: مروجي الإني

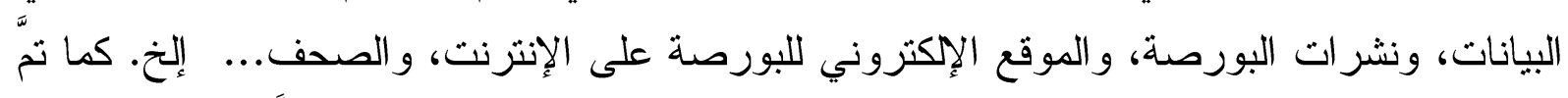

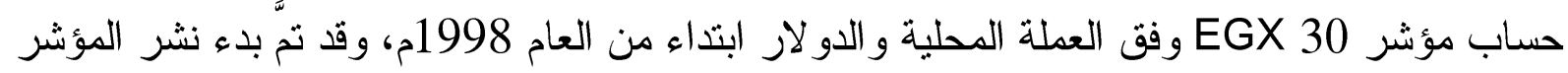
مقوماً بالدو لار في 1 مارس في العام 2009م.

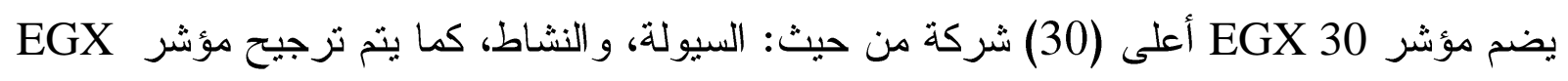

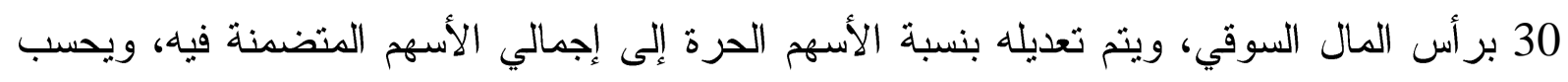

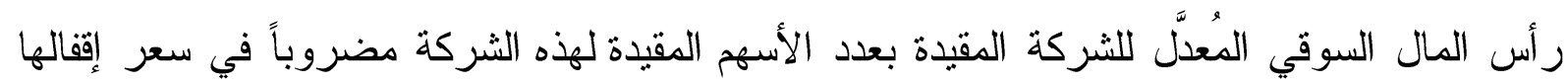

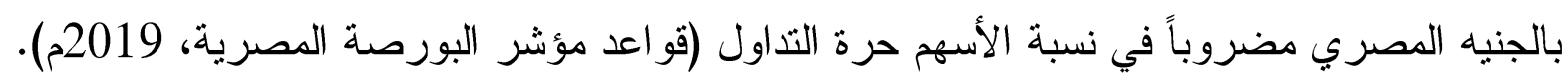
يجب ألا تقل نسبة التداول الحر للشركة عن 15\% كحد أدنى؛ لكي يتم إدراجها في المؤشر، أو ألا تقل

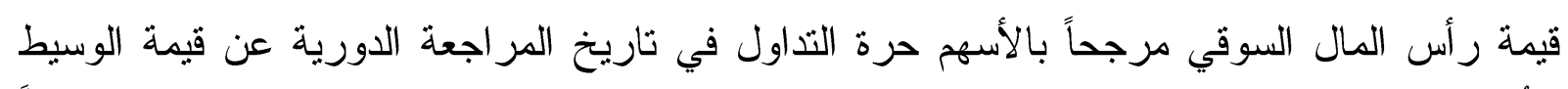

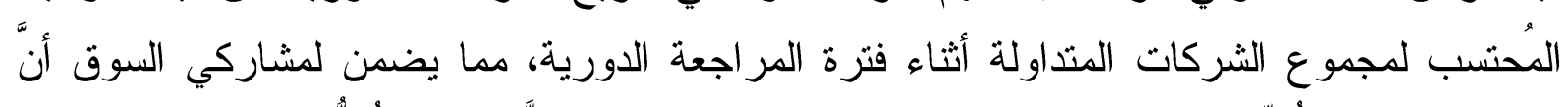

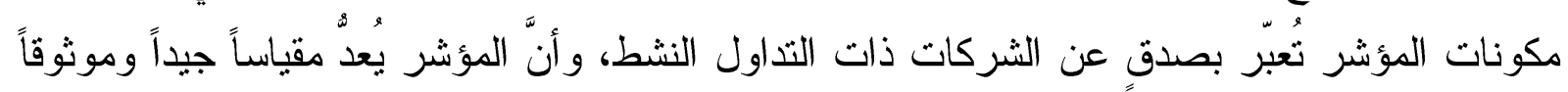
به للسوق المصرية. 
خامساً: أثر متغيرات الاقتصاد الكلي في أداء مؤشر سوق الأوراق المالية

$$
\text { 1- الناتج المحلي الإجمالي }
$$

عُرِّف الناتج المحلي الإجمالي بأنه كمية أو قيمة السلع و الخدمات التي بنتجها أفراد مجتمع محدد

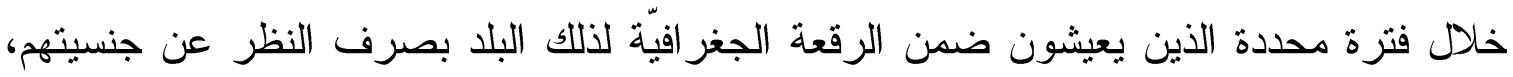

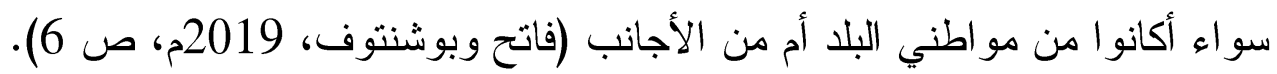

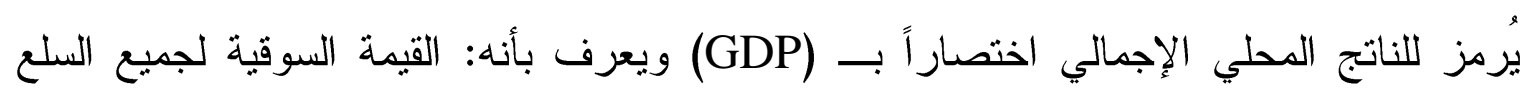

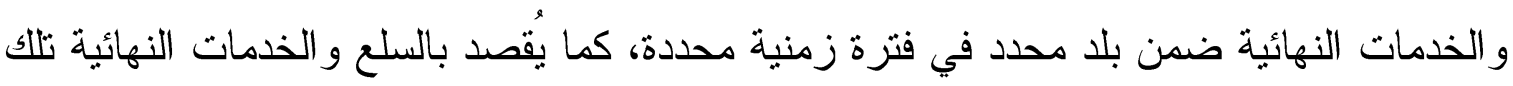
التي تذهب إلى المستهلك النهائي، وليس منتجاً وسيطاً يدخل في إنتاج سلع وخدمات أخرى، فمن المفترض وجود علاقة طردية بين معدل النمو في الناتج المحلي وأسعار الأسهم، فالاقتصاد النشط يولّد أرباحاً جيدة للشركات، ويزيد من الاستثمار في الأسهم (Vejzagic, 2013, P 79).

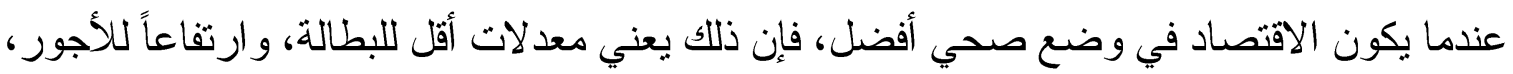
وزيادة في الإنفاق. حيث أن نمو الناتج المحلي الإجمالي بوتيرة منسار عة يدفع معدلات التضخم إلى

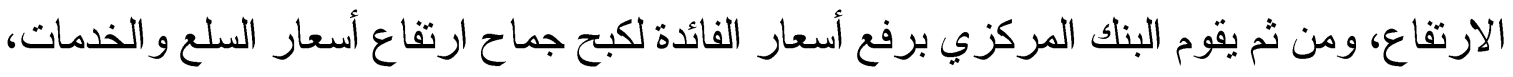
مما يعني ارتفاع تكلفة اقتراض الثركات، ورفع قروض المنازل وشر اء السبارات. أما في حالة

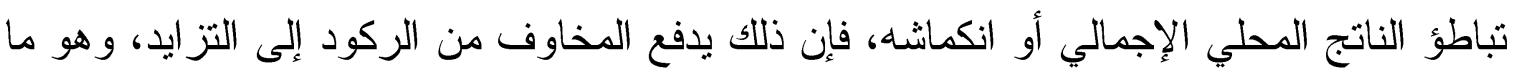
يعني تسريح العمال، وانخفاض معدلات الإنفاق، وتراجع أرباح الثركات، كما يعد تقريز الناتج

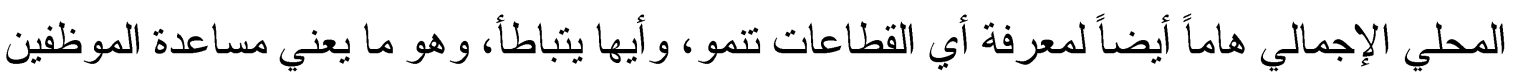
أو العمال نحو التوجه إلى القطاعات الواعدة (بن واضح، 2014، ص 20)

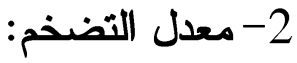

يعتبر التضخم ظاهرة اقتصادية تثير إلى عدم الاستقرار الاقتصادي، وتترجم عادة بارتفاع المستوى

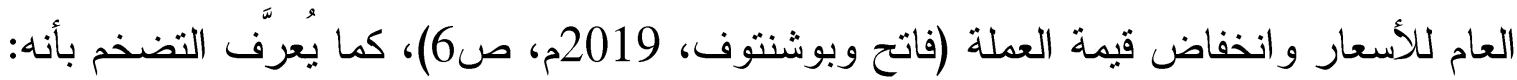

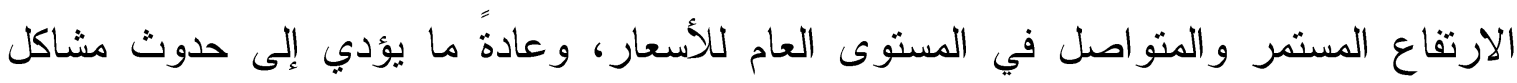

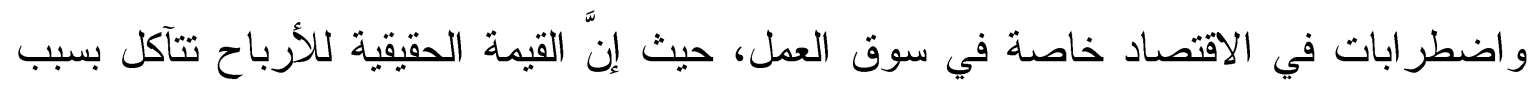

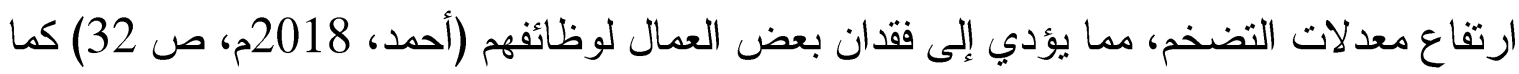

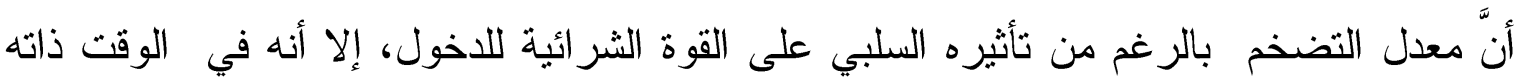
يمارس تأثير اً إيجابياً من خلال زيادة المبيعات وأرباح الثركات، ومن ثم أسعار الأسهر وعو ائدها 
بشكل يفوق الثأثير السلبي، مما يجعل في النهاية من الأسهم استثماراً ناجحاً في أوقات التضخم، وخاصة التضخم المعتدل (سراي، 2017م، ص 74).

بحث الأدب الاقتصادي بموضوع التضخم وعلاقته بأسعار الأسهم من خلال منهجين، الأول يشير إلى إمكانية استخدام الأسهم كوسيلة تحوط كاملة تجاه التضخم، وكانت أراء فيشر المتعلقة بأسعار الفائدة الاسمية والحقيقية الحجة التي استتد إليها الاقتصاديون من بعده، في صياغة فرضية اقترنت باسمه والثي تشير إلى أن المعدلات المتوقعة لعو ائد الأسهم العادية نساوي العوائد الحقيقية زائد

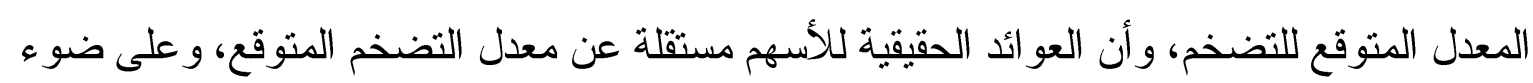
هذه الفرضية توصل بعض الاقتصاديين إلى أن الأسهم وسيلة تحوط كاملة تجاه التضخم طالما أن العو ائد الاسمية تزداد بنفس الزيادة في معدل التضخم أو طالما أن معدل العائد الحقيقي يكون مساوياً

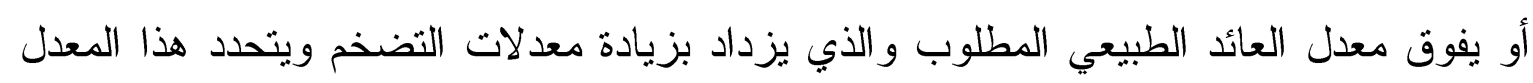
بفعل عو امل ذاتية من قبل المستثرين (سراي، 2017، ص لو

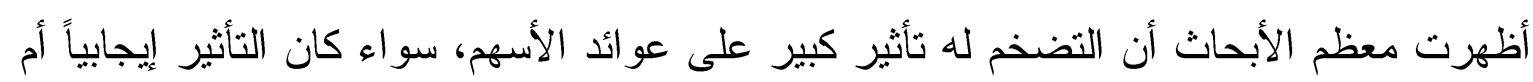
سلبياً، فقد توصلت در اسة (Aminullah et al, 2019) إلى أن العلاقة بين التضخم وعو ائد الأسهم Aminullah ) في روسيا هي علاقة سلبية بينما تبين في الهند و الصين وجود علاقة إيجابية قوية وعنية (et al, 2019, p 108 كما عثرت دراسة (GIRI, 2017) على علاقة إيجابية طويلة الأمد بين معدل التضخم وأسعار الأسهم (giri,2017, p 63 )

إن معدل التضخم على الرغم من تأثيره السلبي على القوة الشر ائية للاخول إلا أند في نفس الوقت يمارس تأثير أ إيجابياً من خلال زيادة المبيعات وأرباح الثركات، ومن ثم أسعار الأسهم وعو ائدها

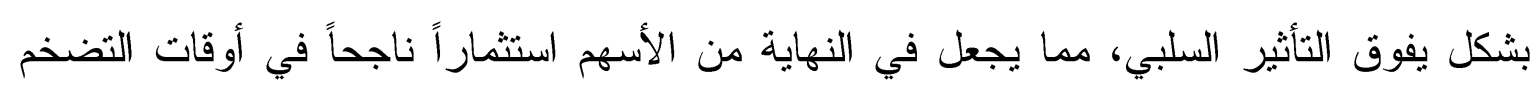

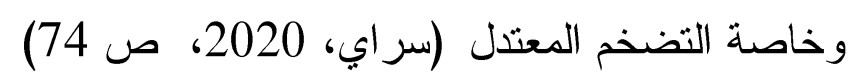
حيث يؤثر التضخم على القرارات الاستثمارية في الأسواق المالية من خلا التأثير على التكلفة

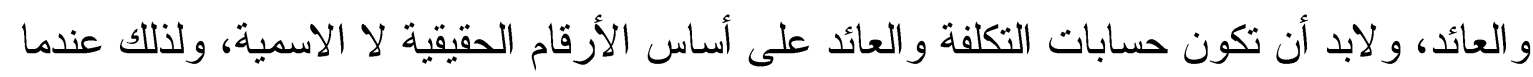

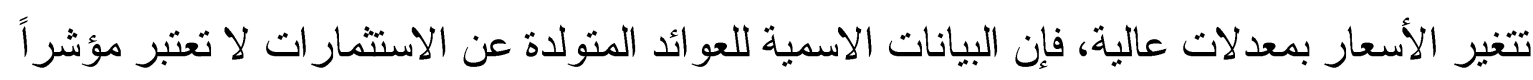

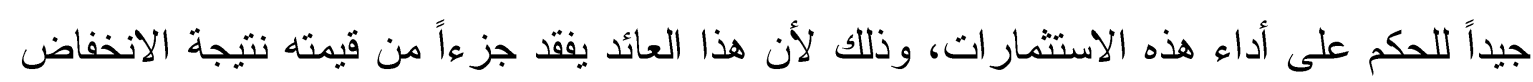


في قوته الثر ائية خلال فترة الاستثمار تبعاً لمعدل التضخم السائد خلال هذه الفترة (سر اي، 2017، ص يفترض "فاما" وجود علاقة عكسية بين التضخم وعو ائد الأسهم، فالعلاقة بين المتغيرات الاقتصادية

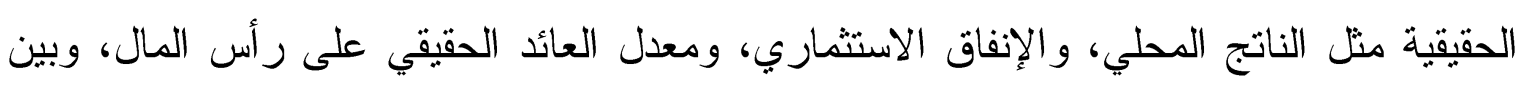
عو ائد الأسهر علاقة طردية، كما أن العلاقة بين هذه المتغير ات و التضخم علاقة عكسية، لذلك فالعلاقة بين التضخم وعو ائد الأسهم هي علاقة عكسية، وقد ظهر في الأدب الاقتصادي، العديد من التفسيرات للعلاقة السلبية بين التضخم وأسعار الأسهم، دنها أن التضخم سيؤدي إلى ارتفاع معدلات الفئه ولائدة، وبالتالي الارتفاع في عو ائد السندات و انخفاض أسعار ها (النيف، 2018، ص 129) حيث تستخدم الأسهم كوسيلة تحوط تجاه التضخم لحماية المستثرين من مخاطر انخفاض القوة الثرائية لوحدة النقد وذلك بافتر اض أن سعر السهم في السوق المالي بستجيب غالباً للظروف هن

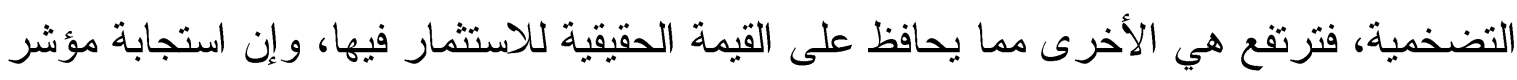

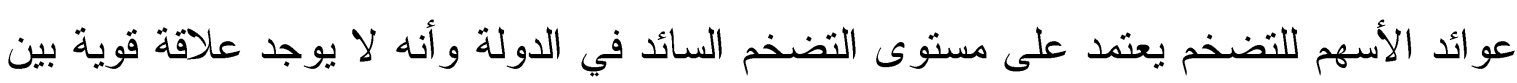
التضخم ومؤشر عوائد الأسهم في الدول ذات معدل التضخم المنخفض ولكن توجد علاقة قوية

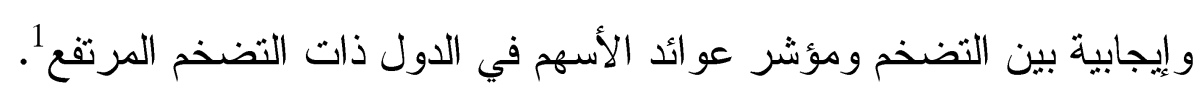
3- معدل الفائدة على الودائع نوجد علاقة عكسية ما بين أسعار الفائدة وأسعار الأسهم في ظل فرضية مفادها: "إنَّ النقود الرخيصة تمكن الأفراد من الحصول على الأتمان المصرفي بأسعار فائدة متدنية والاتجاه نحو سوق الأسهم،

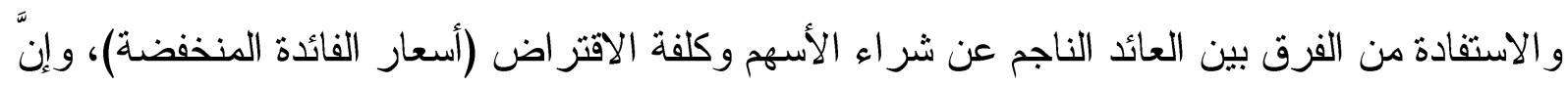

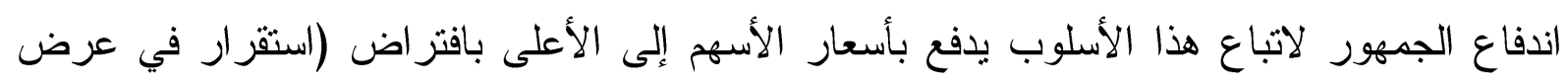

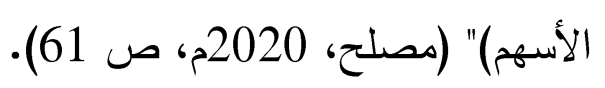

تلعب أسعار الفائدة السائدة في أسوق المال دور اً أساسياً في حركة النقد وبالتالي تساهم في نوجيه الأمو ال عبر الوسطاء من الددخرين إلى المقترضين، وبهذا يعد سعر الفائدة السوقي بمثابة المحرك الأساسي

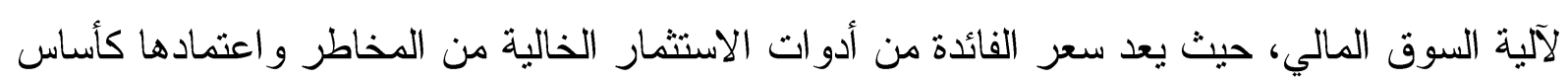
لتحديد العائد المتوقع من الأدوات الاستثمارية المختلفة (سر اي، 2017، ص 90رك)

بتال، أحمد حسين، ومطر، سراب عبد الكريم (2017) أثر التضخم على عو ائد أسهم قطاعات سوق العراق للأوراق المالية:

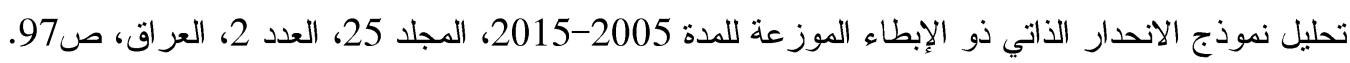


كما تعد أسعار الفائدة إحدى الأدوات الهامة لإدارة السياسة النقدية في الاقتصاد حيث تشتخدمها السلطة النقدية في التأثير على عرض النقود ويتمثل الدور الأساسي لأسعار الفائدة في المساهمة في التخصيص الأمثل للموارد المتاحة، من المدخرات بين الاستثمارات المختلفة، ويرتبط التعامل بالأسواق المالية ارتباطاً وثيقاً بسعر الفائدة نظر اً لارتباط سعر الفائدة بمعظم أدوات التعامل في الأسواق المالية، حيث تساهم أسعار الفائدة المرتفعة في تشجيع الادخار ألا أنها في نفس الوقت تؤدي إلى زيادة تكلفة الاستثمار، وبالتالي فإن تحرك أسعار الفائدة ارثفاعاً وانخفاضاً يتحدد بناءً على الحجم المطلوب من القرض مقارنةً بحجم المعروض من المدخر ات، وتميل أسعار الأسهم إلى التحرك في اتجاه معاكس لأسعار الفائدة طويلة الأجل، وبالتالي فإن البنك المركزي بإمكانه التأثير بطريقة غير مباشرة على أسعار الأسهم من خلال تحكمه بأسعار الفائدة. إن مسألة ما إذا كانت أسعار الأسهم ومعدلات الفائدة متصلة أم لا هي مسألة مهمة وخاصة مع زيادة التجارة الدولية و اندماج الأسواق المالية العالمية فإذا كانت أسعار الأسهم ترتبط بمعدلات الفائدة والعلاقة السببية تتجه من معدلات الفائدة إلى أسعار الأسهم وبذلك يمكن الوقاية من أزمات الأسواق المالية من خلال التحكم بمعدلات الفائدة إضافة إلى إمكانية استفادة البلدان النامية و استغلال هذه القناة لجذب استثار ات المحافظ الأجنبية في بلدانهم، وبالمثل إذا كانت السببية تتجه من أسعار الأسهم إلى معدلات الفائدة فبذلك يمكن للسلطات من التركيز على السياسة الاقتصادية المحلية لتحقيق الاستقر ار في الأسهم. يؤثر التغير في أسعار الفائدة تأثير اً كبير اً على حركة أسعار الأوراق المالية المتذاولة في البورصة سواء كانت أسهماً أم سندات، أن ثأثير سعر الفائدة على الأوراق التي يتكون عائدها من تدفق ثابت كالسندات و الأسهم الممتازة يكون أكبر لأن ارتفاع أسعار الفائدة يجعل من هذه الأوراق المالية غير تتافسية مما يؤدي إلى قيام المستثرين بالتخلص منها بالبيع و اللجوء إلى توظيف الأمو ال في استثمار ات ثدر عائد أعلى وبالتالي فإن ارثفاع أسعار الفائدة ينتج عنه تفادي الاستثمار ذو الدخل الثابت، و التخلص من الأور اق المالية الخاصة بالمؤسسات المالبة مثل البنوك وشركات التأمين التي تتأثر أرباحها كثير اً بتغيرات أسعار الفائدة، وبالتالي فإن توقع ارتفاع أسعار الفائدة بؤدي إلى انخفاض أسعار الأوراق المالية (خليل، 
يعتقد الخبر اء الكينزيين بوجود علاقة سلبية بين أسعار الفائدة وأسعار الأوراق المالية وذلك لأن ارتفاع

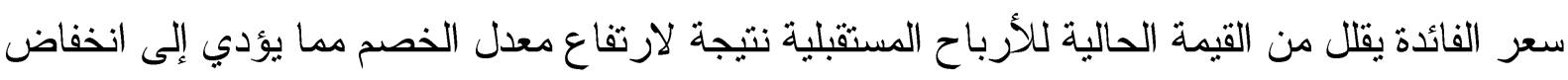
في أسعار الأسهم إضافة إلى انخفاض حجم الاستثمارات نتيجة ارتفاع الفو ائد على القروض بدافع القيام بالأنشطة الاستثمارية، وعلى العكس يؤدي انخفاض أسعار الفائدة إلى انخفاض تكلفة الفرصة البديلة

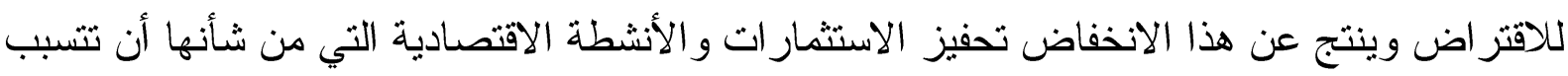

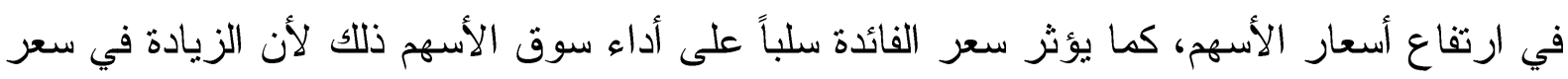
الفائدة من شأنه أن يجعل المستثرين يتجنبون المخاطر العالية، بالاستثمار في سوق الأسهم وميلهم للاستثمار في الأصول ذات المخاطر المنخفضة التي تحمل فائدة ثابتة مثل الودائع الثابتة وشهادات

$$
\text { الادخار و أذونات الخزينة (خليل، 2015،ص لص الاسل }
$$

من المفترض وجود علاقة سلبية بين معدل الفائدة وعو ائد الأسهم لسببين رئيسيين هما: (الثهاب، 2014،

- يؤثر ارتفاع معدلات الفائدة على مستوى أرباح الثركات بسبب ارتفاع تكلفة الديون وبالثالي يتاثثر

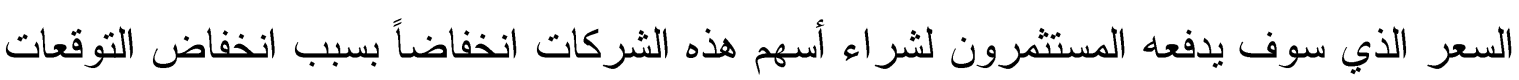

$$
\text { بشأن الأرباح و التوزيعات وعند انخفاض أسعار الفائدة يحدث العكس. }
$$

- يشتري العديد من المستثمرين أسههم من خلال الاقتر اض وبالتالي فعند ارتفاع معدلات الفائدة تصبح تكلفة الاقتراض عالية وسوف يتردد المستثرون في الاقتراض من أجل تحقيق عائد أعلى

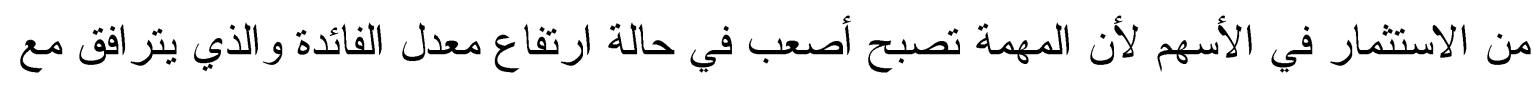
ارتفاع معدل التضخم، وبالتالي سوف ينخفض الطلب الكلي على الأسهر وتتخفض الأسعار .

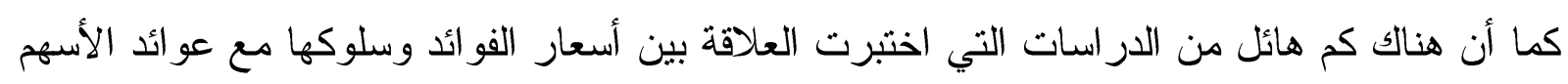

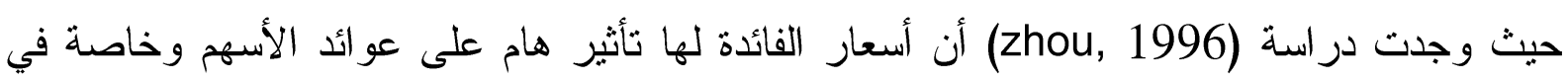
الآجال الطويلة، في سوق الو لايات المتحدة وكذلك التذبذب العالي في عو ائد الأسهم يرتبط بتذبذب عالي في عو ائد السندات طويلة الأجل. (zouh, 1996, p 03) كما بينت دراسة (harasty and roulette, 2000) التي طبقت على أسواق 17 دولة متقدمة حيث بينت الدراسة أن هناك علاقة تكاملية بين عو ائد الأسهم وأسعار الفو ائد طويلة الأجل، وأن هناك علاقة لئة ارتباط سلبية ما بين أسعار الفائدة والمؤشر العام لأسعار الأسهم (Harasty, 2000) 
المناقشة وتحليل النتائج

أو لاً: قياس متغير ات الدر اسة

أ- قياس المتغيرات المسنقلة

معدل الناتج المحلي الإجمالي

جدول رقم (1): الناتج المحلي الإجمالي خلال الفترة (2010-2019) \%

\begin{tabular}{|c|c|}
\hline J المعام & المعام \\
\hline $218.90 \%$ & 2010 \\
\hline $236.00 \%$ & 2011 \\
\hline $279.40 \%$ & 2012 \\
\hline $288.60 \%$ & 2013 \\
\hline $305.50 \%$ & 2014 \\
\hline $332.70 \%$ & 2015 \\
\hline $332.90 \%$ & 2016 \\
\hline $235.40 \%$ & 2017 \\
\hline $250.90 \%$ & 2018 \\
\hline $303.20 \%$ & 2019 \\
\hline
\end{tabular}

www.albankaldawli.org المصدر : الموقع الإكتروني للبنك الدولي

شهد معدل الناتج المحلي الإجمالي ارتفاعاً ملحوظاً خلال الفترة الممتدة ما بين العامين (2010م2016م)، ثم عاود الانخفاض خلال عامي 2017 عامي 2018 ارتفع مجدداً فيما بعد، حيث كان في العام 2016م، العام الأكثر ارتفاعاً في معدل الناتج المحلي الإجمالي، يليه العام 2015م. شكل رقم (1): معدل نمو الناتج المحلي الإجمالي خلال الفترة ما بين عامي (2010-2019)

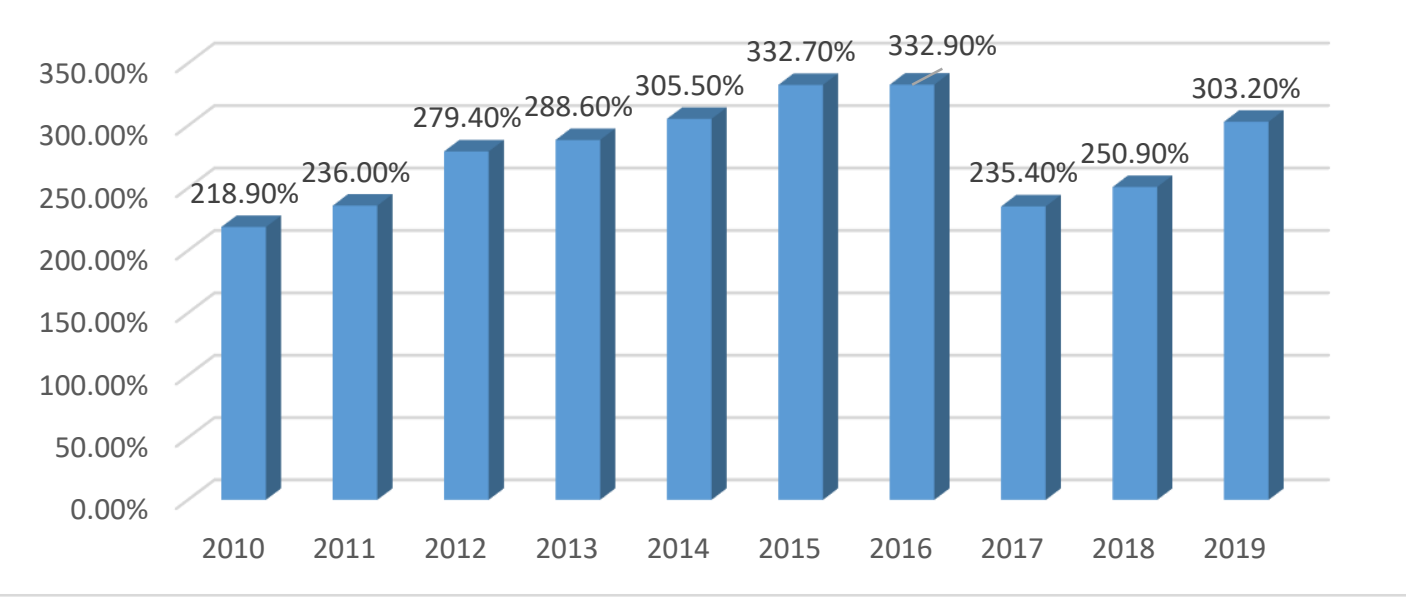

المصدر: إعداد الباحثة بالاعتماد على الجدول أعلاه 
معدل التضخم

جدول رقم (2): معدل التضخم خلال الفترة (2010-2019) \%

\begin{tabular}{|c|c|}
\hline العام & 2010 \\
\hline $11.10 \%$ & 2011 \\
\hline $10.10 \%$ & 2012 \\
\hline $7.10 \%$ & 2013 \\
\hline $9.50 \%$ & 2014 \\
\hline $10.10 \%$ & 2015 \\
\hline $10.40 \%$ & 2016 \\
\hline $13.80 \%$ & 2017 \\
\hline $29.40 \%$ & 2018 \\
\hline $14.50 \%$ & 2019 \\
\hline $9.20 \%$ & \\
\hline
\end{tabular}

www.capmas.gov.eg المصدر: الجهاز المركزي للتعبئة العامة والإحصاء المصري

شهر معدل التضخم انخفاضاً ملحوظاً خلال الفترة الممتدة ما بين عامي (2010م-2012م)، ثم عاود الارتفاع خلال الفترة الممندة ما بين عامي (2013م-2017م) لينخفض مجدداً مع حلول العام 2018م، بلغت أقل قيمة له خلال العام 2012م، أما ذروة التضخم، فقد كانت خلال العام 2017م. شكل رقم (2): معدل التضخم خلال الفترة (2010-2019)

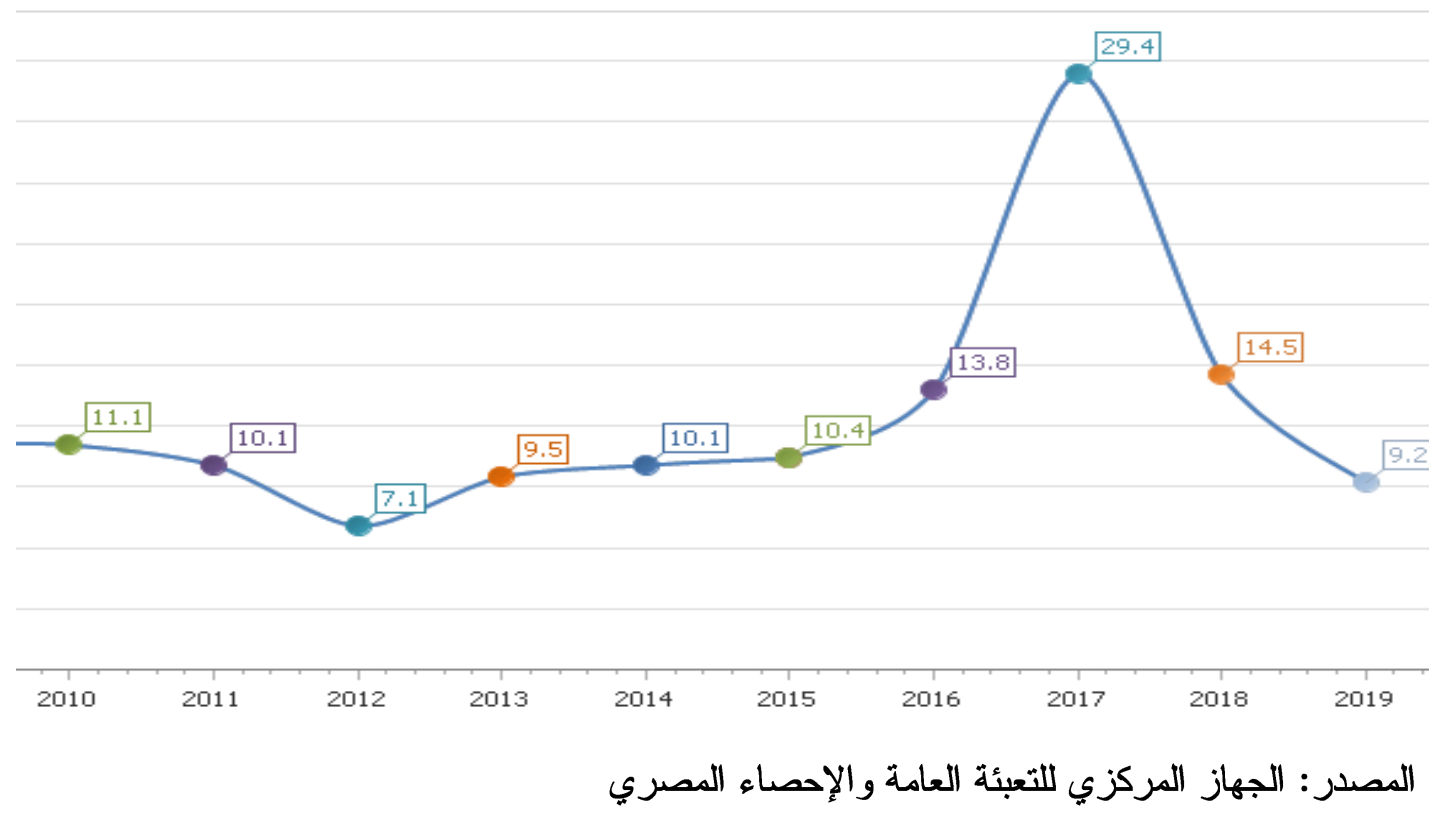


جدول رقم (3): معدل الفائدة على الودائع خلال الفترة (2010 -2019) \%

\begin{tabular}{|c|c|}
\hline (الع| & معدل الفائدة على الودائع| \\
\hline $11.10 \%$ & 2010 \\
\hline $11 \%$ & 2011 \\
\hline $11.90 \%$ & 2012 \\
\hline $12.60 \%$ & 2013 \\
\hline $11.30 \%$ & 2014 \\
\hline $11.60 \%$ & 2015 \\
\hline $13.40 \%$ & 2016 \\
\hline $18 \%$ & 2017 \\
\hline $18.20 \%$ & 2018 \\
\hline $18.22 \%$ & 2019 \\
\hline
\end{tabular}

www.cbe.org.eg المصدر: الموقع الإلكتروني للبنك المركزي المصري

شهدت معدلات الفائدة تذبذباً ملحوظاً خلال الفترة المتدة ما بين عامي (2010م-2014م)، ثم بدأت بالارتفاع فيما بعد عاماً بعد عام.

شكل رقم (3): معدل الفائدة على الودائع خلال الفترة (2010-2019)

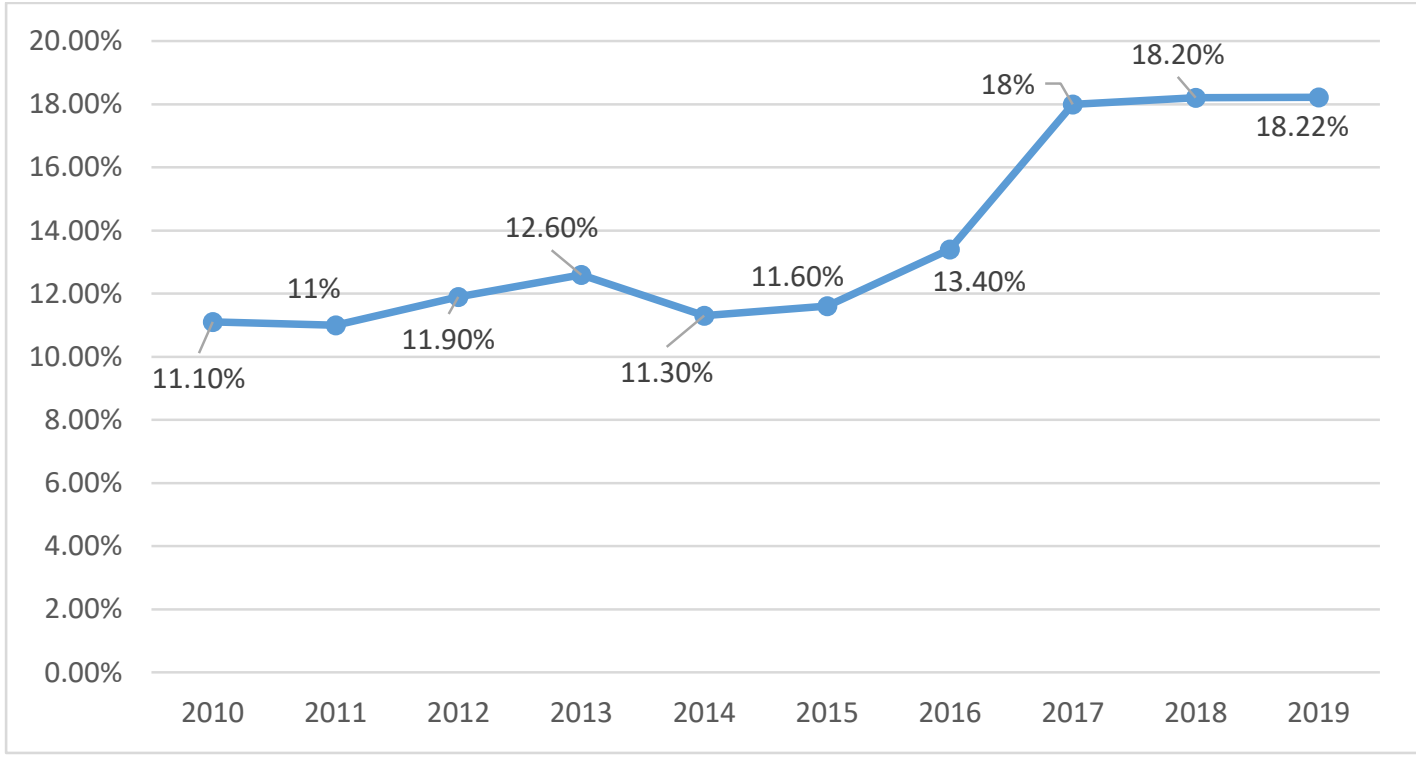

المصدر: إعداد الباحثة بالاعتماد على الجدول أعلاه 
بـ قياس المتغير التابع

مؤشر EGX 30

جدول رقم (4): مؤشر EGX 30 خلال الفترة (2010م-2019م)

(جنيه مصري)

\begin{tabular}{|c|c|}
\hline EGX 30 & 2الع| \\
\hline 7142.14 & 2010 \\
\hline 3622.35 & 2011 \\
\hline 5462.42 & 2012 \\
\hline 6782.84 & 2013 \\
\hline 8926.58 & 2014 \\
\hline 7006.01 & 2015 \\
\hline 12344.89 & 2016 \\
\hline 15019.14 & 2017 \\
\hline 13035.77 & 2018 \\
\hline 13961.56 & 2019 \\
\hline
\end{tabular}

www.egx.com.eg المصدر: الموقع الإكتروني للبورصة المصرية

انخفض مؤشر 2011م 30 خلال العام، ثم عاود الارتفاع مجدداً، وصو لاً إلى العام 2015م الذي شهد أخفض قيمة للمؤشر بلغت (7006.01) بينما عاود الارتفاع خلال العام 2016م-2017م ليعاود

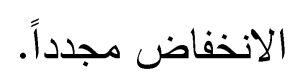

شكل رقم (4): مؤشر EGX 30 خلال الفترة (2010م-2019م)

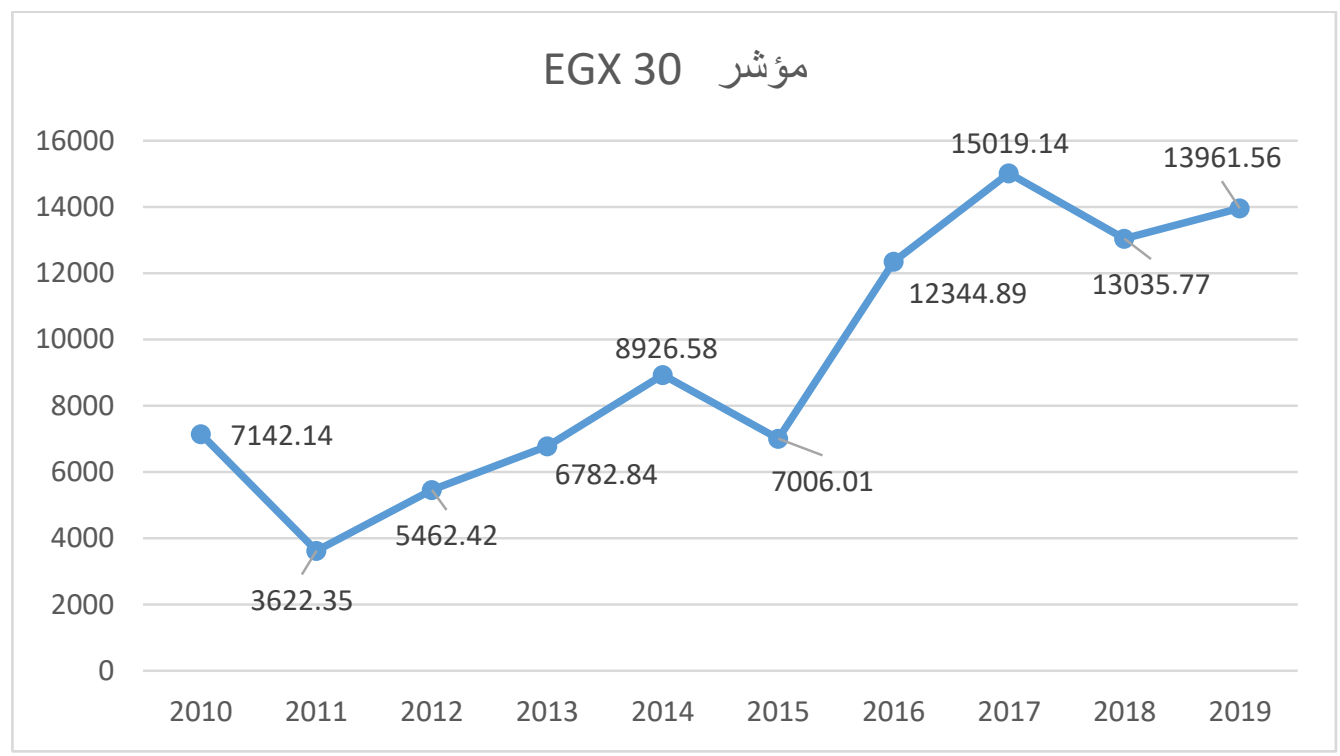

المصدر : إعداد الباحثة بالاعتماد على الجدول أعلاه 
تتضمن الإحصاءات الوصفية قيم كل من: المتوسط الحسابي، و الانحراف المعياري، فضلاً عن معامل الاختلاف من خلال نسبة الانحر اف المعياري إلى الوسط الحسابي، فضلاً عن أكبر وأصغر قيمة. جدول رقم (5): الإحصاءات الوصفية لمتغيرات الدراسة

\begin{tabular}{|c|c|c|c|c|c|}
\hline الاختلاف & الانحراف المعياري & المتوسط الحسابي & أكبر قيمة & أصغر قيمة & \\
\hline c.v\% & Std. Deviation & Mean & Maximum & Minimum & \\
\hline$\% 42$ & 3958.30814 & 9330.3700 & 15019.14 & 3622.35 & EGX 30 المؤشر \\
\hline$\% 15$ & 41.25324 & 278.3500 & 332.90 & 218.90 & الناتج المحلي الإجمالي \\
\hline$\% 50$ & 6.30904 & 12.5200 & 29.40 & 7.10 & معدل التضخم \\
\hline$\% 23$ & 3.12553 & 13.7320 & 18.22 & 11.00 & معدل الفائدة على الودائع \\
\hline
\end{tabular}

المصدر: مخرجات البرنامج الإحصائي Spss

- - بلغ متوسط المؤشر (9330)، وبلغت أكبر قيمة (15019)، وأقل قيمة (3622)، ولدى حساب معامل الاختلاف لمؤشر EGX 30 تبيّن أنه يساوي 42\%، وهذا يعكس وجود تشتت ضعيف في قيم المؤشر بين سنوات الدر اسة. - - بلغ متوسط معدل الناتج المحلي الإجمالي (278.3)، وبلغت أكبر قيمة (332.9)، وأقل قيمة (218.9)، ولدى حساب معامل الاختلاف للناتج المحلي الإجمالي تبيّن أنه يساوي 15\%، وهذا يعكس وجود تشتت ضعيف في معدل الناتج المحلي الإجمالي بين سنوات الدراسة. - - بلغ متوسط معدل التضخم (12.5)، وبلغت أكبر قيمة (29)، و أقل قيمة (7.1)، ولدى حساب معامل الاختلاف لمعدل التضخم تبيّن أنه يساوي 50\%، و هذا يعكس وجود تشتت منوسط في معدل التضخم

$$
\text { بين سنو ات الدر اسة. }
$$

- - بلغ متوسط معدل الفائدة على الودائع (13.7)، وبلغت أكبر قيمة (18.2)، و أقل قيمة (11)، ولدى حساب معامل الاختلاف لمعدل الفائدة على الودائع تبين أنه يساوي 23\%، و هذا يعكس وجود تشتت ضعيف في معدل الفائدة على الودائع بين سنو ات الدر اسة. كما تم استخدام برنامج E-views الإصدار الثاني عشر لإجر اء كل من اختبار السببية واختبار التكامل المشترك و اختبار السلاسل الزمنية. 


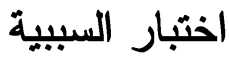

يعتبر الارتباط بين المتغيرات الاقتصادية العنصر الأهم في تحليل الظواهر الاقتصادية غير أن الارنباط

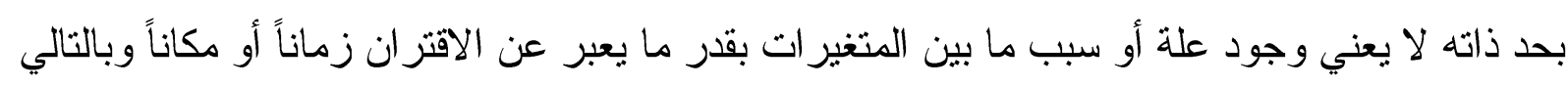
يصعب استخدام تقلب المتغيرات في تفسير ما يحدث بالمتغير ات المرتبطة معها لذلك فأن عدم التعرف

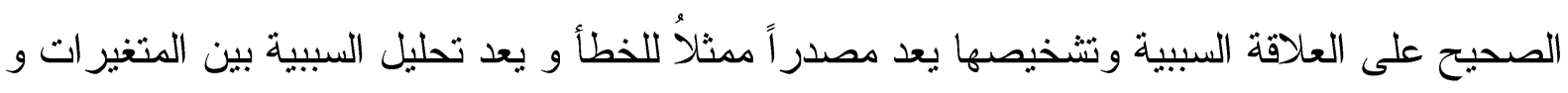
قياسها منهجاً مفضلاً أحياناً في التعرف على العلاقات الاقتصادية مقارنة بمنهج الارتباط و الانحدار الإحصائي. بعد أسلوب السببية منهجاً تجريبياً يساعد على اختبار العلاقة بين المتغيرات و من ثم تحديد اتجاه العلاقة السببية بينها و بالتالي تحديد المتغير التابع و المتغير المستقل وتعد مساهمة Granger الأبرز بين باقي الدر اسات التي تعرضت لدفهوم السببية و طبقاً له إذا كان لدينا سلسلتان زمنيتان تعبران عن نطور ظاهرتين اقتصاديتين مختلفتين عبر الزمن t وكانت السلسلة $Y_{t}$ تحتوي على المعلومات التي من خلالها يمكن تحسين التوقعات بالنسبة للسلسلة المتغير X إذاً نقول عن متغير أنه سبب فيما إذا كان يحتوي على معلومات تساعد على تحسين التوقع

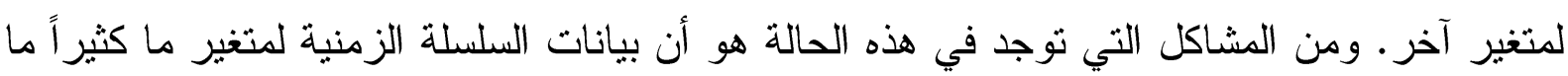
تكون مرتبطة، أي يوجد ارتباط ذاتي بين قيم المتغير الواحد عبر الزمن، ولاستبعاد أثر هذا الارتباط الذاتي إن وجد، ينم إدر اج قيم نفس المتغير التابع لعدد من الفجوات الزمنية كمتغير ات تفسيرية في علاقة السبيية المر اد قياسها، يضاف إلى ذلك إدراج قيم المتغير التقسيري لعدد من الفجوات الزمنية كمتغيرات تفسيرية أيضاً، وذلك باعتبار أن السبب يسبق النتيجة في الزمن. بناءً على ما سبق، ينطلب اختبار السبيية Granger

$$
\begin{aligned}
& Y_{t}=\alpha_{0}+\sum_{i=1}^{p} \beta_{i} Y_{t-i}+\sum_{i=1}^{p} \varphi_{I} X_{t-i}+\mu_{1 t} \\
& X_{t}=\delta_{0}+\sum_{i=1}^{p} \omega_{i} X_{t-i}+\sum_{i=1}^{p} \theta_{I} Y_{t-i}+\mu_{2 t}
\end{aligned}
$$$$
\text { حيث } \mu_{1 t} \text { ، } \mu_{2 t} \text { تنل بو اقي النموذجين (1) ، (2) . }
$$

يتطلب اختبار Grange استخدام المتغيرات بصيغتها المستقرة ،لأن غياب صفة الاستقرار قد يجعل

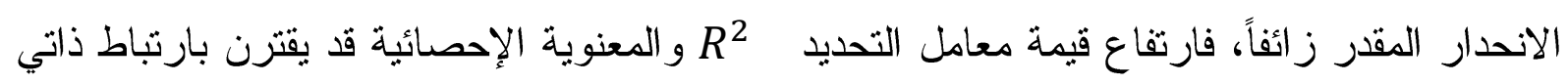
متسلسل، حيث تؤثر ظروف معينة على المتغيرات جميعها لتجعلها تتغير باتجاه واحد مع انعدام العلاقة 
وتتمتل خطوات اختبار Granger بما يلي :

- مقدير الصيغة المقيدة: ونقصد بها المعادلة:

$$
Y_{t}=\alpha_{0}+\sum_{i=1}^{p} \beta_{i} Y_{t-i}+\varepsilon_{1 t} \quad 3
$$

التي تفترض أن يكون Y، ثم نحصل على مجموع مربعات البو اقي المقدرة المستخرجة من معادلة الصيغة المقيدة (3). - تقدير الصيغة غير المقيدة: التي تتمثل في المعادلة (1)، ومن ثم نسنطيع الحصول على مجموع مربعات البو اقي المقدرة المستخرجة من معادلة الصيغة غير المقيدة (1). -

$F_{C}=\frac{\left(\sum \varepsilon_{1 t}^{\Lambda^{2}}-\sum \mu_{1 t}^{2}\right) / P}{\sum \mu_{1 t}^{2} /(n-k)}$

F

حيث (n): حجم العينة، K : عدد المعالم المقدرة في الصيغة غير المقيدة، N-K: درجات الحريى للصيغة غير المقيدة.

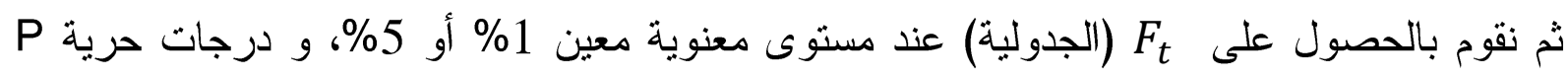
للبسط و n-K للمقام، ستخدم اختبار Fل للحم على وجود علاقة سبية من عدمها بين المتغير ات، ويكون

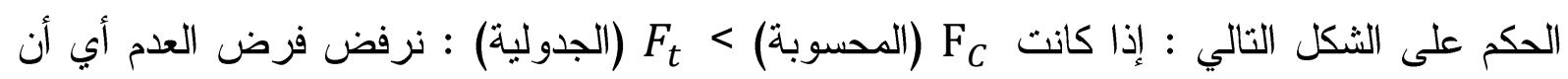

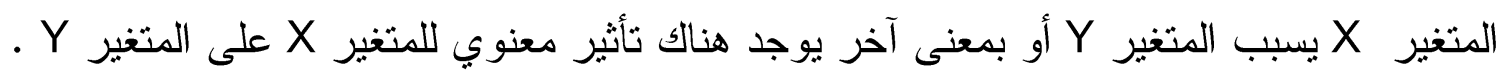
- نقوم بتكر ار نفس الخطو ات السابقة بالنسبة للمعادلة رقم (2)، وبهذا يكون ليدنا أربع نتائج محتملة

لاختبار السبية ل Granger هي على النحو الثالي:

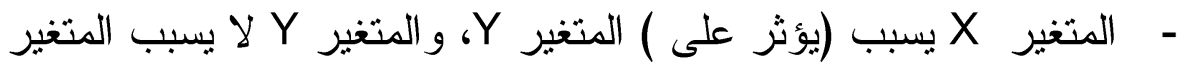

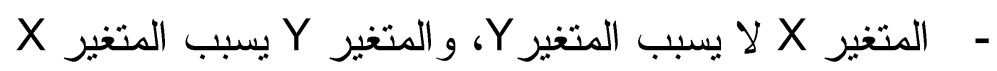
X يسبب المتغير Y، و المتغير X يسبب المتغير X

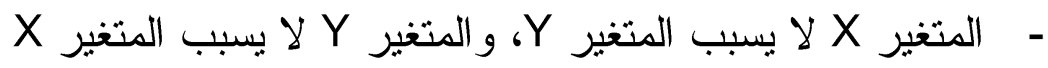




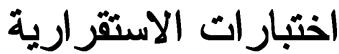

تفترض كل الدراسات التطبيقية التي تستخدم بيانات سلسلة زمنية أن هذه السلسلة مستقرة أو ساكنة stationary وفي حال غياب صفة الاستقر ار stationary فإن الانحدار الذي نحصل عليه بين متغير ات السلسلة الزمنية غالباً ما يكون زائفاً Spurious². و هناك عدة طرق يمكن بواسطتها اختبار سكون السلاسل الزمنية أهمها اختبار جذر الوحدة Unit Root Test الزمنية للمشاهدات، و التأكد من مدى استقر ارها وتحديد رثبة تكامل كل متغير على حدى. وسيتم الاعتماد على اختبار Augmented Dicky Fuller و واختبار Phillps - Perron حيث يعد اختبار فيليبس بيرون أكثر موثوقية من ناحية طبيعة البيانات حيث ير اعي عدم وجود تجانس بين بواقي معادلة ADF، هو يأخذ بالاعتبار قيود أقل على حد الخطأ العشو ائي. وتقوم فرضيات كلا الاختبارين على النحو الثالي: H0 H1 السلسلة الزمنية مستقرة (لا تحتوي على جذر وحدة).

عطيه، عبد القادر . (2014). الحديث في الاقتصاد القياسي بين النظرية و التطبيق. الدار الجامعية. الطبعة الر ابعة. الاسكندرية. 2.

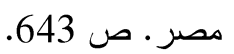

${ }^{3}$ Fuller, Wayne. (2009). Introduction to Statistical Time Series. $2^{\text {nd }}$ Ed. John Wiley and Sons. New York.

${ }^{4}$ Davidson, Russell. MacKinnon. James G. (2004). Econometric Theory and Methods. Oxford University Press. New York. p. 613. 
جدول رقم (6): مخرجات الاسنقرارية بين متغيرات الاقتصاد الكلي

ومؤشر أداء سوق الأوراق المالية المصرية

\begin{tabular}{|c|c|c|c|c|c|c|c|c|c|}
\hline \multicolumn{3}{|c|}{ الفرق الأول } & \multicolumn{3}{|c|}{ الفرق الأول } & \multicolumn{3}{|c|}{ المستوى } & \multirow[t]{2}{*}{ الاختبار } \\
\hline مع ثابت & مع ثابت & ثاتجاه عام & مع ثابت & مع ثابت & اتجاه عام & مع ثابت & مع ثابد & بداه & \\
\hline & & & & & -2.11 & -1.89 & -2.57 & 1.03 & الناتج المحلي الإجمالي \\
\hline & & & & & -4.23 & -1.70 & -1.89 & -0.76 & معدل التضخم \\
\hline & & -4.41 & -1.64 & -2.18 & -1.91 & -1.39 & -0.27 & 2.19 & معدل الفائدة \\
\hline & & & & & & -7.64 & -0.43 & 1.25 & EGX30 \\
\hline \multicolumn{10}{|c|}{ القيم الدرجة } \\
\hline & & -2.93 & -5.83 & -4.58 & -2.88 & -5.52 & -4.42 & -2.84 & $\% 1$ \\
\hline & & -2 & -4.24 & -3.32 & -1.99 & -4.10 & -3.2 & -1.98 & $\% 5$ \\
\hline & & -1.59 & -3.59 & -2.80 & -1.59 & -3.51 & -2.77 & -1.60 & $\% 10$ \\
\hline
\end{tabular}

E-views المصدر: مخرجات البرنامج

يلاحظ من الجدول أن المتغيرات استقرت في رثب مختلفة حيث استقر المتغير التابع عند الفرق المستوى في حين استقر متغيران الناتج المحلي الإجمالي ومعدل التضخم عند الفرق الأول واستقر متغير معدل الفائدة على الودائع عند الفرق الثاني وبالتالي لا يوجد نكامل مشترك بين المتغيرات لأن من شروط التكامل المشترك أن تستقر جميع المتغير ات المدروسة عند نفس الرتبة. لار اسة سبيية غر انجر يجب تحديد درجة التأخر المثلى وذلك من خيار VAR ونظر اً لصغر حجم العينة لم ينقبل البرنامج هذا الأمر لذلك تم تحديد درجة تأخر سنة واحدة وقد تم التوصل إلى النتائج التالية 
جدول رقم (7): مخرجات سببية غرانجر بين متغيرات الاقتصاد الكلي

ومؤشر أداء سوق الأوراق المالية المصرية

Pairwise Granger Causality Tests

Date: 12/19/21 Time: 12:30

Sample: 20102019

Lags: 1

\begin{tabular}{lccc}
\hline \hline Null Hypothesis: & Obs & F-Statistic & Prob. \\
\hline \hline DGDP does not Granger Cause EGX30 & 8 & 0.76781 & 0.4210 \\
EGX30 does not Granger Cause DGDP & & 0.48904 & 0.5155 \\
\hline \hline DI does not Granger Cause EGX30 & 7 & 0.11505 & 0.7515 \\
EGX30 does not Granger Cause DI & & 0.82992 & 0.4138 \\
\hline \hline DINF does not Granger Cause EGX30 & \multirow{2}{*}{8} & 0.23209 & 0.6503 \\
EGX30 does not Granger Cause DINF & & 0.22334 & 0.6564 \\
\hline \hline
\end{tabular}

E-views المصدر : مخرجات البرنامج

1- المتغير ان الناتج المحلي الإجمالي و EGX30 الحالة الأولى: فرض العدم الناتج المحلي الإجمالي

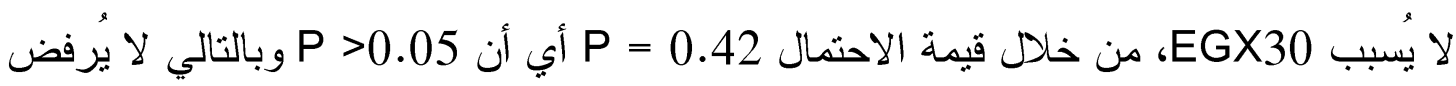
فرض العدم أي الناتج المحلي الإجمالي لا يسبب EGX30، الحالة الثانية: فرض العدم EGX30 P > لا يُبب الناتج المحلي الإجمالي، من خلال قيمة الاحتمال

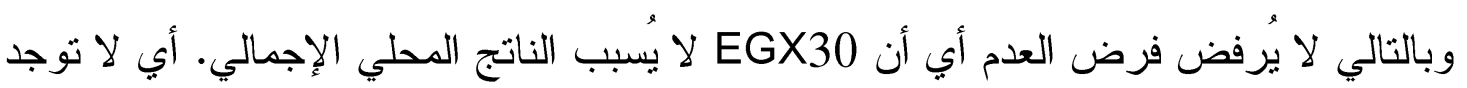
علاقة سببية بين المتغيرين بالاتجاهين.

2- المتغير ان معدل الفائدة على الودائع و EGX30 الحالة الأولى: فرض العدم معدل الفائدة على الودائع لا يُسبب EGX30، من خلال قيمة الاحتمال 0.75 = 0.7 أي أن

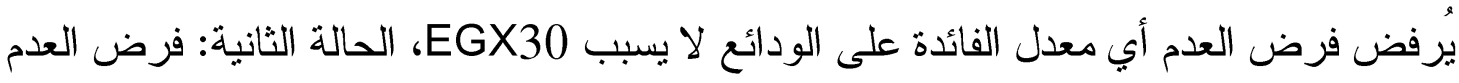
لا يُسبب معدل الفائدة على الودائع، من خلا قيمة الاحتمال EGX30 و وبالتالي لا يُرفض فرض العدم أي أن EGX30 > لا يُسبب معدل الفائدة على الودائع. أي لا توجد علاقة سبيية بين المتغيرين بالاتجاهين.

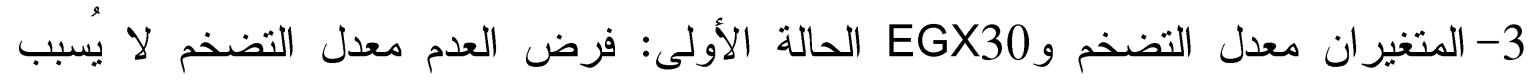
EGX30

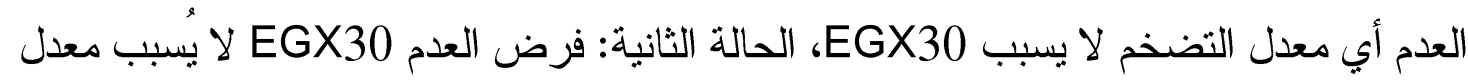

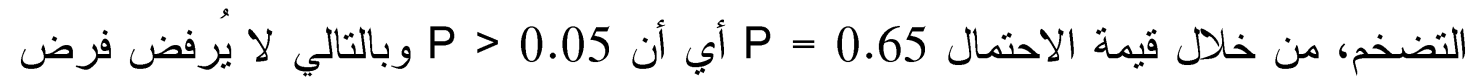


العدم أي أن EGX30 لا يُسبب معدل الفائدة على الودائع. أي لانوجد علاقة سبيية بين المتغيرين بالاتجاهين.

$$
\text { التكامل المشترك بطريقة انجل - غر انجر }
$$

ترنكز نظرية التكامل المشترك على تحليل السلاسل الزمنية غير المستقرة، إذ يشير كل من العالمين Granger \& Engle المستقرة. وإذا أمكن توليد هذا المزيج الخطي المستقر، تعتبر السلاسل الزمنية غير المستقرة في هذه الحالة متكاملة من نفس الرتبة. ويشترك لنطبيق اختبار التكامل المشترك هو أن تكون المتغيرات قيد الدراسة منكاملة من نفس الدرجة. إذا كان ليدنا Y،X متغيران غير مستقرين بالمستوى ومتكاملين من نفس الدرجة، عندئذ نتبع منهج ذي الخطوتين ، وفق التسلسل التالي : (Engle\&Granger) المرحلة الأولى: ثقدير معادلة انحدار العلاقة طويلة الددى بواسطة طريقة المربعات الصغرى الاعتيادية

$$
Y_{t}=\alpha+\beta X_{t}+Z_{t}
$$

حيث استخدمنا مستوى المتغيرات في الانحدار (أي المتغيرات غير المستقرة في المستوى). نستخرج من معادلة انحدار التكامل المشترك السابقة البواقي المقدرة:

$$
\stackrel{\Lambda}{Z}_{t}=Y_{t}-\stackrel{\Lambda}{\alpha}-\stackrel{\Lambda}{\beta} X_{t}
$$

ومن أجل التأكد من أن المتغيرين قيد الدرا سة متكاملان تكاملاً هـ شتركاً يجب اختبار استقرار البواقي باستخدام اختبار (A.D.F) - (A)

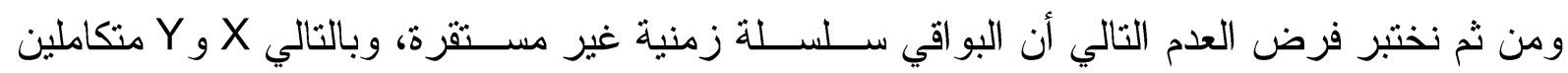
تكاملاً مشتركاً. ينم اجر اء نموذج انحدار متعدد بحيث يكون المتغير الثابع هو EGX30 و المتغيرات المستقلة (الناتج المحلي الإجمالي، معدل الفائدة على الودائع، معدل التضخم)، وذلك بتشكيل سلسلة البواقي لمعادلة الاتحدار وذلك لدراسة استقرارية سلسلة البو اقي حيث يجب أن تكون مستقرة عند هذا المستوى. 
ثم يتم اجر اء نموذج انحدار المتغير التابع هو الفرق الأول لسلسة البواقي و المتغير التابع هو أبطاء سلسلة البو اقي بتأخر زمنية سنة واحد.

جدول رقم (8): التكامل المشترك بين متغيرات الاقتصاد الكلي

ومؤشر أداء سوق الأوراق المالية المصرية

Dependent Variable: D(UT)

Method: Least Squares

Date: 12/19/21 Time: 14:01

Sample (adjusted): 20112019

Included observations: 9 after adjustments

\begin{tabular}{lrllr}
\hline \hline \multicolumn{1}{c}{ Variable } & Coefficient & Std. Error & t-Statistic & Prob. \\
\hline \hline \multicolumn{1}{c}{ UT(-1) } & -1.459273 & 0.261685 & -5.576439 & 0.0008 \\
\multicolumn{1}{c}{ C } & -271.6561 & 357.6634 & -0.759530 & 0.4723 \\
\hline \hline R-squared & 0.816257 & Mean dependent var & -191.7317 \\
Adjusted R-squared & 0.790008 & S.D. dependent var & 2339.620 \\
S.E. of regression & 1072.128 & Akaike info criterion & 16.98581 \\
Sum squared resid & 8046216. & Schwarz criterion & 17.02964 \\
Log likelihood & -74.43614 & Hannan-Quinn criter. & 16.89123 \\
F-statistic & 31.09667 & Durbin-Watson stat & 1.966400 \\
Prob(F-statistic) & 0.000836 & & \\
\hline \hline
\end{tabular}

E-views المصدر: مخرجات البرنامج

بالنظر إلى قيمة معامل الانحدار للمتغير المستقل UT(-1 نجدها نساوي -1.45 وبالنظر لمعنوية هذا المتغير نجده يساوي 0008.00 أي أنه معنوي عند مستوى معنوية 5\% وبالتالي يوجد علاقة طويلة الأجل بين المتغير ات المستقلة و المتغير التابع اختبار فرضية الدراسة يوجد أثر ذو دلالة معنوية للمتغيرات الاقتصادية الكلية: (معدل الناتج المحلي الإجمالي، ومعدل التضخم، ومعدل الفائدة على الودائع) في أداء مؤشر سوق الأوراق المالية المصرية EGX 30 . بغرض اختبار الفرضية تمّ إجر اء اختبار الانحدار الخطي المتعدد لاختبار أثز متغيرات الاقتصاد الكلي: (معدل الناتج المحلي الإجمالي، ومعدل التضخم، ومعدل الفائدة على الودائع) كمتغير مستقل في المتغير التابع أداء مؤشر سوق الأوراق المالية المصرية EGX 30 . 
جدول رقم (9): الدلالة الإحصائية لاختبار العلاقة بين متغيرات الاقتصاد الكلي

و أداء مؤشر سوق الأوراق المالية المصرية EGX 30.

\begin{tabular}{|c|c|c|c|c|}
\hline Std. Error of the Estimate & $\begin{array}{c}\text { Adjusted R } \\
\text { Square }\end{array}$ & R Square & R & Model \\
\hline $\mathbf{1 6 8 5 . 9 9 5 6 3}$ & $\mathbf{0 . 8 1 9}$ & $\mathbf{0 . 8 7 9}$ & $\mathbf{0 . 9 3 8}$ & 1 \\
\hline
\end{tabular}

المصدر : مخرجات البرنامج الإحصائي Spss

يتضح من الجدول أعلاه أنَّ قيمة معامل الارتباط R تساوي (0.938)، وهو ما يبين وجود ارتباط قوي

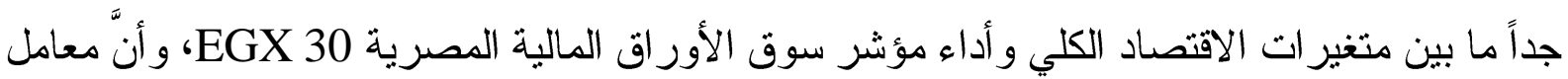

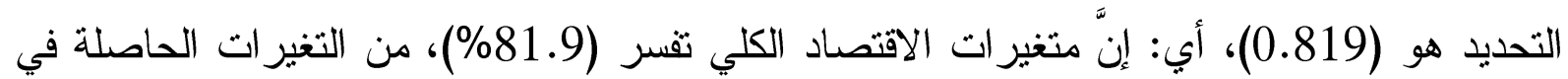

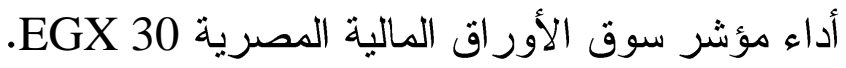
جدول رقم (10): الدلالة الإحصائية لاختبار القوة التفسيرية لتباين نموذج الدراسة

\begin{tabular}{|c|c|c|c|c|c|c|}
\hline \multicolumn{6}{|c|}{ ANOVA $^{\mathrm{a}}$} \\
\hline Sig. & F & Mean Square & Df & Sum of Squares & \multicolumn{2}{c|}{ Model } \\
\hline 0.004 & 14.536 & 41319447.420 & 3 & 123958342.300 & Regression & \multirow{2}{*}{} \\
\hline & & 2842581.264 & 6 & 17055487.580 & Residual & 1 \\
\hline & & & 9 & 141013829.800 & Total & \\
\hline
\end{tabular}

المصدر : مخرجات البرنامج الإحصائي SpsS

يبين الجدول أعلاه تحليل التباين الذي يمكن من خلاله معرفة الدلالة الإحصائية للقوة التفسيرية للنموذج عن طريق إحصائية F، و هي (14.536)، ومعنوية الدلالة الحسابية (sig= (0.004)، مما يؤكد الدلالة الإحصائية لنموذج الانحدار الخطي من الناحية الإحصائية، أي: النموذج بشكل عام معنوي. 
جدول رقم (11): الدلالة الإحصائية لنموذج الدراسة لأثر المتغيرات المستقلة متغيرات الاقتصاد الكلي في أداء مؤشر سوق الأوراق المالية المصرية EGX 30 .

\begin{tabular}{|c|c|c|c|c|c|}
\hline \multirow{2}{*}{ Sig. } & \multirow{2}{*}{ T } & $\begin{array}{c}\text { Standardized } \\
\text { Coefficients }\end{array}$ & \multicolumn{2}{|c|}{ Unstandardized Coefficients } & \multirow{2}{*}{ Model } \\
\cline { 3 - 6 } & & Beta & Std. Error & B & \\
\hline 0.032 & $-2.786-$ & & 4964.021 & -13827.784 & الثابnn \\
\hline 0.100 & 1.942 & 0.296 & 14.629 & 28.404 & X1 \\
\hline 0.118 & 1.824 & 0.334 & 114.811 & 209.440 & X2 \\
\hline 0.006 & 4.210 & 0.726 & 218.490 & 919.735 & X3 \\
\hline
\end{tabular}

المصدر : مخرجات البرنامج الإحصائي SpsS

يشير الجدول أعلاه إلى أن الدلالة الإحصائية (معدل الناتج المحلي الإجمالي) هي غير دالة إحصائياً حسب قيمة t المحسوبة، وهي تساوي (1.942)، و الدلالة الإحصائية (0.1) أكبر من (5\%)، وبالتالي، يتم رفض الفرضية البديلة، حيث لا بوجد أثز معنوي ذو دلالة إحصائية لمعدل الناتج المحلي الإجمالي في أداء مؤشر سوق الأوراق المالية المصرية EGX 30 . كما أن (معدل التضخم) غير دال إحصائياً حسب قيمة t المحسوبة، وهي تساوي (1.824)، و الدلالة الإحصائية (0.118) أكبر من (5\%)، وبالتالي، يتم رفض الفرضية البديلة، حيث لا بوجد أثر معنوي ذو دلالة إحصائية لمعدل التضخم في أداء مؤشر سوق الأوراق المالية المصرية EGX 30. كما أن (معدل الفائدة على الودائع) دال إحصائياً حسب قيمة t المحسوبة، وهي تساوي (4.210) و الدلالة الإحصائية (0.006) أصغر من (5\%)، وبالتالي، يتم رفض فرضية العدم وقبول الفرضية البديلة، حيث يوجد أثز معنوي ذو دلالة إحصائية لمعدل الفائدة على الودائع في أداء مؤشر سوق الأوراق المالية

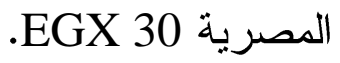
وبالتالي يوجد أثز معنوي ذو دلالة إحصائية لمتغيرات الاقتصاد الكلي (معدل الفائدة على الودائع) في أداء مؤشر سوق الأوراق المالية المصرية EGX 30. تكون معادلة الانحدار على الشكل الآتي:

$$
y=-13827.78+919.735 x 3
$$

حيث إن ارتفاع معدل الفائدة على الودائع بنسبة 1\% يؤدي إلى تحسين أداء مؤشر سوق الأوراق المالية

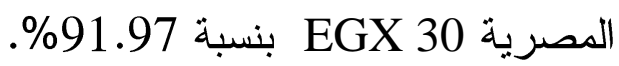


وبالثالي، يوجد أثر إيجابي لمعدل الفائدة على الودائع في أداء مؤشر سوق الأوراق المالية المصرية .EGX 30

حيث إنّ ارتفاع معدل الفائدة على الودائع يجعل الأفراد يحجمون عن إيداع أمو الهم واستثمارها في البنوك، ويتوجهون إلى الاستثمار في السوق المالي، مما ينعكس إيجاباً على مؤشر سوق الأوراق المالية. النتائج و المقترحات أولاً: النتائج في ضوء اختبار الفرضيات توصلت الدراسة إلى النتائج الآتية: 1- يوجد أثز إيجابي ذو دلالة معنوية لمعدل الفائدة على الودائع في أداء مؤشر سوق الأوراق المالية المصرية EGX 30 حيث اتفقت الدراسة الحالية مع معظم الدراسات السابقة في وجود أثز إيجابي لمعدل الفائدة على الودائع في أداء مؤشر سوق الأور اق المالية.

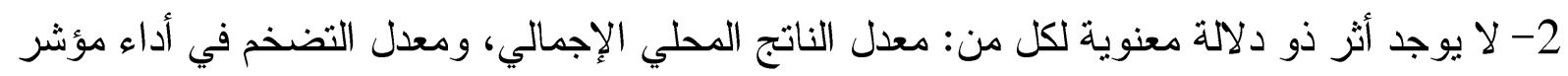

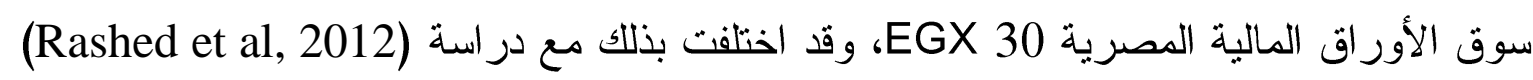

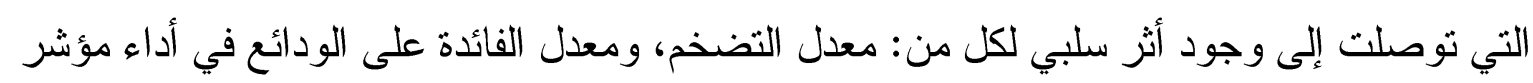
سوق الأوراق المالية.

\section{ثانياً: المقترحات}

$$
\text { في ضوء النتائج السابقة، فإن الباحثة توصي بما يلي: }
$$

1- يمكن للمستثرين في سوق الأوراق المالية المصري أن يأخذوا بالحسبان التغيرات الحاصلة في الاقتصاد الكلي كعو امل ههمة ومؤثرة عند اتخاذ القرار الخاص بالاستثمار في الأسهر. 2- ضرورة قيام السلطة النقدية بالأخذ بالحسبان الآثار الناجمة عن التغير في أسعار الفائدة على نشاط سوق الأوراق المالية عند صياغتها لأي قرارات تهدف إلى تحقيق النمو الاقتصادي. 


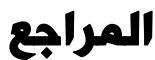

\section{أو لاً: مراجع باللغة العربية \\ الكتب}

- كهينة، رشام (2016م) محاضرات في الأسواق المالية، جامعة آكلي محند أولحاج البويرة، كلية العلوم

الاقتصادية و التجارية وعلوم التنسيير، الجزائر.

- مداحي، محمد (2018م) محاضر ات في الأسو اق المالية، جامعة آكلي محند أولحاج - البويرة، كلية العلوم

الاقتصادية و التجارية و علوم التسيير، الجزائر .

- يونس، محمد (2016) الاقتصاد الدولي و التجارة الخارجية، القاهرة، دار التعليم الجامعي، مصر .

الدوريات

- - بن عمر، بن حاسين (2013م) فعالية الأسواق المالية في الدول النامية- دراسة قياسية، أطروحة دكتور اه،

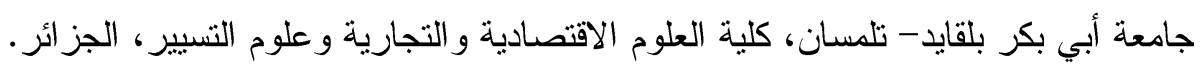

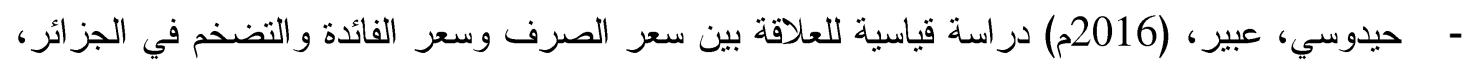

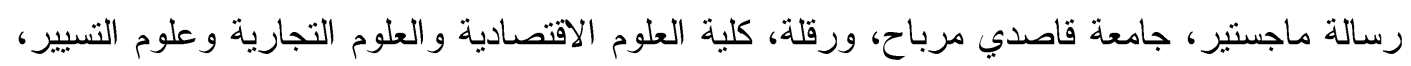

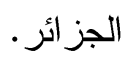

- خليل، فاطمة صالح (2015) أثر المتغير ات النقدية في عو ائد الأسهم في الأسو اق الناشئة، رسالة ماجستير ، جامعة دمشق، كلية الاقتصاد، دمشق، سورية.

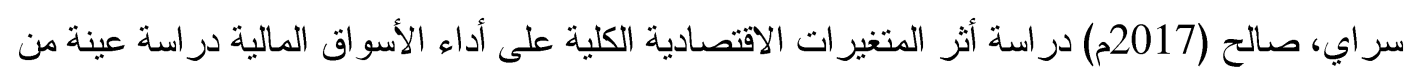

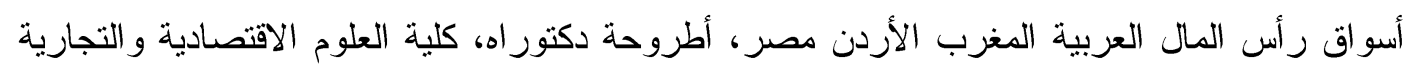
و ولوم التسيير، جامعة محمد بوضياف المسيلة، الجزائر.

فاتح، جميلة، وبوشنتوف، نور الهدى (2019م) أثر متغيرات الاقتصاد الكلي: (التضخم، و النانج المحلي

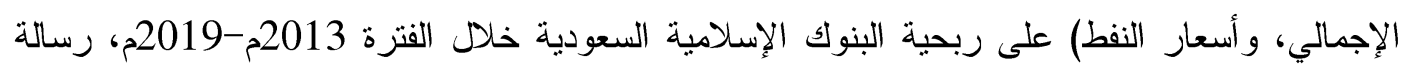
ماجستير، جامعة أحمد دراية - أدرار، كلية العلوم الاقتصادية و التجارية و علوم التسيير، الجزائر.

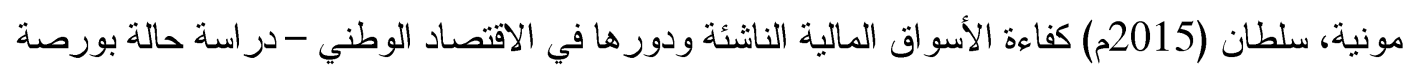

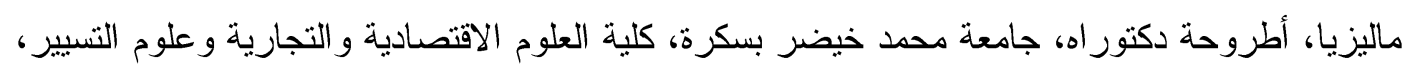

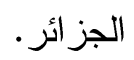




\section{بحث أو ورقة عمل}

- أحمد، زينب عبد الواحد (2018م) أثر التضخم على متغيرات الاقتصاد الكلي في السودان (1990م2015م)، مجلة الدراسات العليا، جامعة النيلين، الدجلد 12، العدد 46، السودان. - آل طعمة، حيدر حسين (2014م) الأسواق المالية: النشأة، المفهوم، الأدوات، سلسلة كر اسات استر اتيجية، مركز الدراسات الاستر اتيجية، جامعة كربلاء، العراق. - بن واضح، الهاثمي (2014)، مساهمة قطاع خدمة الهاتف النقال في الناتج المحلي الإجمالي 2014/2003، مجلة العلوم الاقتصادية و التسيير و العلوم التجارية، العدد 14، الجزائر. - بتال، أحمد حسين، ومطر، سراب عبد الكريم (2017) أثر التضخم على عو ائد أسهم قطاعات سوق العراق للأور اق المالية: تحليل نموذج الانحدار الذاتي ذو الإبطاء الموزعة للمدة 2005-2015، المجلد 25، العدد

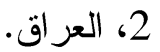
- الزبيدي، سليم رشيد عبود، والمعموري، عامر عمران كاظم (2011م) أثز تقلبات أسعار الصرف على المؤشر العام لأسعار الأسهم دراسة تطبيقية في سوق العر اق للأوراق المالية للمدة 2005م-2011م، مجلة الإدارة و الاقتصاد، المجلد الثالث، العدد الثاني عشر، العرا. سراي، صالح، وبن مرزوق، نبيل (2020) دراسة اقتصادية تحليلية لأثر التضخم على مؤشرات أداء السوق المالية: حلة سوق عمان للأوراق المالية للفترة 1980-2015، مجلة بحوث الإدارة والاقتصاد،

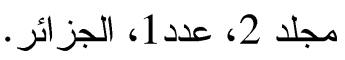
- الثهاب، أيمن (2014) تحديد أثر المؤشرات الاقتصادية الكلية على عائد مؤشر السوق المالي في الأسواق المالية الناشئة - حالة سوقي دمثق وعمان الماليين، مجلة جامعة البعث، المجلد 36، العدد 11، سورية. - صالح، حميد علي، ونايف، عبد القادر (2020م) قياس أثر بعض المتغيرات الاقتصادية الكلية في ظاهرة البطالة في العر اق للمدة 2003م-2018م، مجلة در اسات محاسبية ومالية، المجلد 15، العدد 50، العر اق. - مصلح، أسامة جبار (2020م) أثز تغير عرض النقود على أسعار الأسهم لسوق العراق للأور اق الماليةدر اسة تحليلية، مجلة الدنانين، العدد الثامن عشر، العراق. - منولي، سمر مصطفى منصور (2016م) تحليل ومقارنة أساليب تصميم مؤشرات أسواق الأوراق المالية: مثال مؤشرات أسواق الو لايات المتحدة ومصر، المجلة العربية للعلوم ونشر الأبحاث، المجلد الثاني، العدد

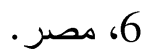
- النيف، خالد لافي (2018) العلاقة الديناميكية بين متغيرات الاقتصاد الكلي و المؤشر العام لبورصة عمان للأوراق المالية، المجلة الأردنية للعلوم الاقتصادية، المجلد 5، العدد 2، الأردن. - قو اعد مؤشر البورصة المصرية، الموقع الإككتروني للبورصة المصرية، 2019م. 


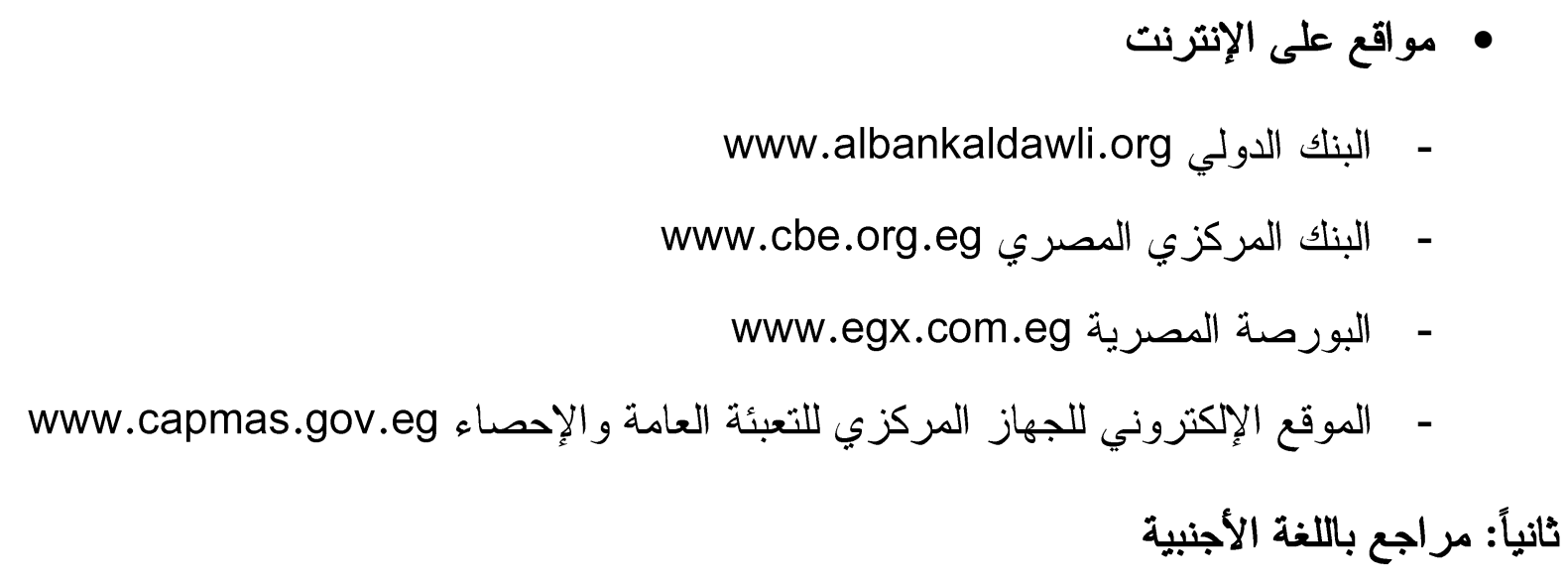

- Barakat. Ramadan; Sara, Elgazzar and Khaled, Hanafy (2016). Impact of Macroeconomic Variables on Stock Markets: Evidence from Emerging Markets, International Journal of Economics and Finance, 8 (1).

- El-Nader, Hasan and Alraimony Ahmad (2012). The Impact of Macroeconomic Factors on Amman Stock Market Returns, International Journal of Economics and Finance; (4) 12: 202-213.

- Rashid, M., Ahmad, K., Azim, P. and Ur Rehman, H, (2012) "Measuring the Impact of Inflation on Conditional Stock Market Volatility in Pakistan: An Application of GARCH Model," Middle Eastern Finance and Economics, 13: 36-40.

- Muthike and Sakwa (2011). Can macroeconomic indicators be used as predictors of the stock exchange index trends? A look at the Nairobi stock exchange, Available at: http://journals.jkuat.ac.ke/index.php/jscp/article/viewFil e/731/676.

- Tarazi, Daniel Goyeau et.Amin (2006) "La Bourse", 2 e édition, France.

- Tiryaki, Ahmet, Levent Erdogan, Reşat Ceylan (2017) the Causal Relationship between Selected Macroeconomic Variables and Stock Returns in Turkey, International Journal of Economic and Administrative Studies

- Vejzagic, Mirza. Zarafat, Hashem. "Relationship between Macroeconomic Variables and Stock Market Index: Co-Integration Evidence from FTSE Bursa Malaysia Hijrah Shariah index”, Asian Journal of Management Science and Education, Vol. 2, No. 4, (2013),

- Aminullah Assagaf ,Etty ,Murwaningsari „Juniati ,Gunawan ,Sekar ,Mayangsari (2019) The Effect of Macro Economic Variables on Stock Return of Companies That Listed in Stock Exchange :Empirical Evidence from Indonesia ,International Journal of Business and Management ; Vol ,14 .No ,8 .p108

- GIRI A. K, JOSHI Pooja (2017) The Impact of Macroeconomic Indicators on Indian Stock Prices: an Empirical Analysis, Studies in Business and Economics no. 12.(1)p63

- Zouh, c (1996) stock market fluctuations and the term structure, board of governors of the federal reserve system, finance and economics discussion series: 69/03.

- Harasty, h, roulette (2000) modeling stock market returns, journal of portfolio management, vol 26, no 2. 